NASA/TM-2003-212114

\title{
Iced Aircraft Flight Data for Flight Simulator Validation
}

Thomas P. Ratvasky, Kurt Blankenship, William Rieke, and David J. Brinker Glenn Research Center, Cleveland, Ohio 
Since its founding, NASA has been dedicated to the advancement of aeronautics and space science. The NASA Scientific and Technical Information (STI) Program Office plays a key part in helping NASA maintain this important role.

The NASA STI Program Office is operated by Langley Research Center, the Lead Center for NASA's scientific and technical information. The NASA STI Program Office provides access to the NASA STI Database, the largest collection of aeronautical and space science STI in the world. The Program Office is also NASA's institutional mechanism for disseminating the results of its research and development activities. These results are published by NASA in the NASA STI Report Series, which includes the following report types:

- $\quad$ TECHNICAL PUBLICATION. Reports of completed research or a major significant phase of research that present the results of NASA programs and include extensive data or theoretical analysis. Includes compilations of significant scientific and technical data and information deemed to be of continuing reference value. NASA's counterpart of peerreviewed formal professional papers but has less stringent limitations on manuscript length and extent of graphic presentations.

- TECHNICAL MEMORANDUM. Scientific and technical findings that are preliminary or of specialized interest, e.g., quick release reports, working papers, and bibliographies that contain minimal annotation. Does not contain extensive analysis.

- CONTRACTOR REPORT. Scientific and technical findings by NASA-sponsored contractors and grantees.
- CONFERENCE PUBLICATION. Collected papers from scientific and technical conferences, symposia, seminars, or other meetings sponsored or cosponsored by NASA.

- SPECIAL PUBLICATION. Scientific, technical, or historical information from NASA programs, projects, and missions, often concerned with subjects having substantial public interest.

- TECHNICAL TRANSLATION. Englishlanguage translations of foreign scientific and technical material pertinent to NASA's mission.

Specialized services that complement the STI Program Office's diverse offerings include creating custom thesauri, building customized databases, organizing and publishing research results ... even providing videos.

For more information about the NASA STI Program Office, see the following:

- Access the NASA STI Program Home Page at http://www.sti.nasa.gov

- E-mail your question via the Internet to help@sti.nasa.gov

- Fax your question to the NASA Access Help Desk at 301-621-0134

- Telephone the NASA Access Help Desk at 301-621-0390

- Write to:

NASA Access Help Desk

NASA Center for AeroSpace Information 7121 Standard Drive

Hanover, MD 21076 
NASA/TM-2003-212114

\section{Iced Aircraft Flight Data for Flight Simulator Validation}

Thomas P. Ratvasky, Kurt Blankenship, William Rieke, and David J. Brinker Glenn Research Center, Cleveland, Ohio

Prepared for the

General Aviation Technology Conference and Exhibition 2002

sponsored by the Society of Automotive Engineers

Wichita, Kansas, April 16-18, 2002

National Aeronautics and

Space Administration

Glenn Research Center 


\section{Acknowledgments}

The authors wish to thank the engineering and technical staff at the NASA Glenn hangar for the outstanding effort to complete this flight project in a safe and thorough manner. Special recognition goes to Dan Gorman and Steve

Hayes for their diligence and dedication to quality craftsmanship, and to Mary Ann Dembowski for her support in preparing this report. We also would like to thank the NASA Aviation Safety Program (AvSP) System Wide Accident Prevention (SWAP) Project for sponsoring this effort.

Trade names or manufacturers' names are used in this report for identification only. This usage does not constitute an official endorsement, either expressed or implied, by the National Aeronautics and Space Administration.

Available from

NASA Center for Aerospace Information 7121 Standard Drive

Hanover, MD 21076
National Technical Information Service 5285 Port Royal Road Springfield, VA 22100 


\title{
Iced Aircraft Flight Data for Flight Simulator Validation
}

\author{
Thomas P. Ratvasky, Kurt Blankenship, William Rieke, and David J. Brinker \\ National Aeronautics and Space Administration \\ Glenn Research Center \\ Cleveland, Ohio 44135
}

\begin{abstract}
NASA is developing and validating technology to incorporate aircraft icing effects into a flight training device concept demonstrator. Flight simulation models of a DHC-6 Twin Otter were developed from wind tunnel data using a subscale, complete aircraft model with and without simulated ice, and from previously acquired flight data. The validation of the simulation models required additional aircraft response time histories of the airplane configured with simulated ice similar to the subscale model testing. Therefore, a flight test was conducted using the NASA Twin Otter Icing Research Aircraft.
\end{abstract}

Over 500 maneuvers of various types were conducted in this flight test. The validation data consisted of aircraft state parameters, pilot inputs, propulsion, weight, center of gravity, and moments of inertia with the airplane configured with different amounts of simulated ice. Emphasis was made to acquire data at wing stall and tailplane stall since these events are of primary interest to model accurately in the flight training device. Analyses of several datasets are described regarding wing and tailplane stall. Key findings from these analyses are that the simulated wing ice shapes significantly reduced the $C_{L} \max$, while the simulated tail ice caused elevator control force anomalies and tailplane stall when flaps were deflected $30^{\circ}$ or greater. This effectively reduced the safe operating margins between iced wing and iced tail stall as flap deflection and thrust were increased.

This flight test demonstrated that the critical aspects to be modeled in the icing effects flight training device include: iced wing and tail stall speeds, flap and thrust effects, control forces and control effectiveness.

\section{INTRODUCTION}

In response to a White House Initiative to reduce aviation accidents, NASA formed the Aviation Safety Program (AvSP) in 1999. This seven-year program has been tasked to reduce aviation accident rates by $80 \%$ by 2007 and by $90 \%$ by 2017 . Accident and incident reports were analyzed to focus efforts on areas of highest return. These studies showed that $13 \%$ of all weatherrelated accidents were due to airframe icing.

One approach to reduce the icing hazard was to increase pilot awareness through improved training programs. NASA developed a number of tools to supplement pilot training that consist of educational \& training videos ${ }^{1,2}$ and computer-based training materials ${ }^{3}$. Additionally, a task within the System Wide Accident Prevention Project of AvSP is currently underway to develop a piloted flight simulator that incorporates icing effects for pilot training applications. The Piloted Flight Simulator for Aircraft Icing Effects Training task is developing technology to provide pilots a pre-exposure to the adverse effects of icing on airplane performance, stability and control. The intent is to develop a tool for initial and recurrent pilot training to increase awareness of the consequences of an icing encounter and the knowledge of how to manage adverse maneuvers that may result from icing-induced loss of control.

In order to develop this technology, the NASA Glenn Research Center teamed with Bihrle Applied Research and the Wichita State University in 1998 to develop an icing effects flight training device concept demonstrator. The aircraft selected for the initial flight simulation demonstrator was a DeHavilland DHC-6 Twin Otter. This selection was made for two primary reasons: 1) the NASA Twin Otter was equipped with research quality instrumentation for cloud physics and flight dynamics measurements and 2) NASA owns and operates the Twin Otter as an Icing Research Aircraft and has extensive operational experience with it in icing conditions.

A number of steps were taken to develop an accurate and robust icing effects flight simulator. The general approach was to use a combination of experimental data from wind tunnels (using sub-scale, complete airplane models with ice shapes), and limited flight data to derive aerodynamic flight characteristics. Initial efforts were 
devoted to exploring the feasibility of measuring the incremental effects of artificial ice shapes on small-scale wind tunnel models (approx 12\%-scale). After measurement feasibility was assured, the efforts were focused to develop small-scale ice shapes for smallscale (approximately 7\%-scale) wind tunnel models to obtain equivalent full-scale iced aeroperformance characteristics ${ }^{4}$. This was a substantial and critical step in order to develop accurate simulation models. After the ice shape development methods were understood, a $6.5 \%$-scale complete aircraft model of a Twin Otter was fabricated and tested at the Wichita State University 7'x10' Low Speed Wind Tunnel and the Bihrle Applied Research Large Amplitude Multi-Purpose Wind Tunnel to obtain static and dynamic force and moment coefficient data. The force and moment coefficient data from these wind tunnels along with previously gathered flight data served as the basis of the icing effects flight simulator models ${ }^{5}$.

Additional flight test data was required in order to validate the flight simulation models - specifically the "All Iced" (ICE02) configuration. Thus, a flight test activity was developed using the NASA Twin Otter to acquire the full-scale flight dynamics of an ice-contaminated aircraft. This report documents the aircraft and research instrumentation, simulated ice shapes, and flight test maneuvers. The report also shows results from several maneuvers comparing baseline to the iced aircraft performance. A discussion follows on the effects of ice on the wing stall and tail stall characteristics that are essential for the development and validation of the flight training device concept demonstrator.

\section{RESEARCH AIRCRAFT}

The NASA Icing Research Aircraft - N607NA (Figure 1) is a modified DeHavilland DHC-6 Twin Otter. It is powered by two 550 shaft horse power (SHP) Pratt and Whitney PT6A-2 turbine engines driving three-bladed Hartzell constant speed propellers. The flight controls are mechanically operated through a system of cables and pulleys. Control surfaces consist of elevator, ailerons, rudder, and wing flaps. The horizontal tailplane has a fixed stabilizer with an elevator and trim tab.

\section{INSTRUMENTATION SYSTEMS}

The research data acquisition systems enabled measurement and recording of the 1) aircraft dynamics, 2) wing \& tailplane surface pressure, and 3) video documentation of wing \& tailplane flow visualization and pilot actions. The aircraft dynamics data set included: inertial data (body-axis linear accelerations, body-axis angular rates, and pitch, roll and heading angles), air data (angles of attack and sideslip, airspeed, altitude \& temperature), control deflection data (aileron, elevator, rudder, flap, column, yoke and throttle positions), pilot forces, and engine parameter data (propeller RPM, engine torque pressure, and fuel flow). This data set was essential to validate the flight simulation models.
The wing and tailplane aero-performance data set consisted of surface pressures acquired from pressure belts wrapped chord-wise around the right wing (Figure 2 ) and around the stabilizer and elevator (Figure 3). Also tail inflow and velocities were measured using a 5-hole flow probe on the stabilizer. The surface pressures were transmitted through 0.125 " OD strip-tube to Scannivalve pressure transducers mounted in a pod under the right wing for the wing pressure belt, and in the aft section of the fuselage for the tailplane pressure belt and flow probe. This data set was obtained to correlate with similar measurements from wind tunnel tests of the $6.5 \%$-scale model.

Flow visualization of the wing was accomplished by mounting a video camera to the top of the fuselage in line with the leading edge of the wing (Figure 4). Flow visualization of the tailplane was made with a video camera mounted within a fairing on the bottom aft section of the fuselage with a field-of-view of the lower left-hand horizontal tail (Figure 5). Yarn tufts were attached in a matrix of spanwise and chordwise positions on the upper surface of the right wing and lower surface of the left tail to visualize the flow separation and reattachment in various zones along the chord. This enabled researchers to monitor and report separation characteristics in flight to the pilots. A third video camera was installed in the flight deck with an overthe-shoulder view of the pilots to record the pilot actions during the maneuvers (Figure 6). All of these video signals were annotated with time, relevant engineering unit data, and recorded to digital video with an audio record of the intercom comments made by the pilots and engineers.

\section{SIMULATED ICE SHAPES}

The ice shapes for the entire Piloted Flight Simulator for Aircraft Icing Effects Training activity (sub-scale wind tunnel model through flight) were developed using the FAA icing certification envelope (FAR 25 Appendix C) and criteria for a failed ice protection system. The ice shapes were determined using the LEWICE Version 2.0 computer code and the following conditions:

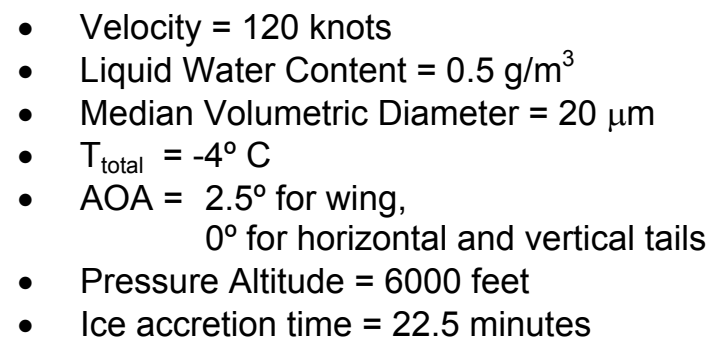

Input geometries consisted of the full-scale geometric coordinates for the Twin Otter wing, horizontal and vertical tail sections. Since the Twin Otter wing and horizontal tail are straight with no twist or taper, one constant cross-section ice shape was determined (Figure 7 and Figure 8). Due to the swept and tapered geometry of the vertical tail, multiple runs of the LEWICE 
code were made to determine the variation in ice shape as a function of the vertical tail span and chord (Figure 9 and Figure 10).

The simulated ice shapes were fabricated from Styrofoam ${ }^{\circledR}$ blocks using templates defined by the LEWICE geometries and hot-wire cutting tool (Figure 11). This method created segments of the ice shapes that spanned about 24 inches each. Grit roughness (2030 grit size) was bonded to the ice shapes to simulate ice roughness characteristics (Figure 12).

The simulated ice shapes were mounted to the Twin Otter in a "build-up" process described below. The mounting method was to directly bond the simulated ice shapes to the airfoil surface using RTV silicone adhesive (Figure 13). This method enabled ice shapes to be secured to the airplane for the duration of the test flights to minimize hazards due to asymmetric ice contamination. The ice shapes were checked as part of the daily pre-flight and monitored during the flight with the video systems. None of the simulated ice shapes debonded from the airplane throughout the flight test.

\section{FLIGHT TEST PROCEDURES}

A general description of the flight test process and maneuvers is described in the sections below.

\section{QUALIFICATION AND RESEARCH FLIGHT PROCESS}

Flight tests were conducted with the Twin Otter in a noice baseline configuration and then the simulated ice shapes were added in a "build-up" manner. Initial ice shape testing was done with the horizontal tail ice only (ICE01 configuration for simulation models). This configuration was flight-qualified to determine safe operating limits in terms of airspeed and flap deflections, after which flight test maneuvers for simulation validation, as described in the next section were performed. After completing the tests with ICE01 configuration, the wing ice shape was mounted to the inboard 1/3 span of the wing, and flight-qualified as before with an emphasis on wing stall characteristics. This process was repeated for 2/3-span and full-span of wing ice with the horizontal tail ice configuration. Finally, the vertical tail ice was added to complete the "All Iced" configuration (ICE02 for simulation models). Note, no ice shapes were added to the wing struts or gear struts. Qualification flights with this configuration established the iced airplane single-engine climb speed $\left(\mathrm{V}_{\text {yse }}\right)$ and minimum controllable airspeed $\left(\mathrm{V}_{\mathrm{mca}}\right)$. Additionally, limits in sideslip were determined to avoid complete vertical tail stall. After establishing the operating limits, maneuvers for the simulation validation effort were performed.

\section{FLIGHT TEST MANEUVERS}

Maneuvers selected for this project were developed to acquire airplane response characteristics for validating the flight simulation models. Maneuvers were initiated from trimmed steady level conditions that covered the full range of the flight envelope (low AOA to high AOA) as determined from the qualification flights. Emphasis was placed on recording airplane response for the reduced operating envelope resulting from ice contamination. As such, maneuvers were conducted with configurations beyond the manufacturers recommended flight envelope (the DHC-6 operations manual limits flap deflections to $10^{\circ}$ in icing conditions).

Below is a brief description of the maneuvers performed for "No-Ice" baseline and each simulated ice configuration. For each, a figure containing time history plots of relevant data is provided to illustrate the maneuvers.

Elevator Doublets: The aircraft was initially trimmed for level flight with specific flap and throttle setting to maintain $\mathrm{C}_{\mathrm{T}}$ for a specified airspeed. The pilot then input a sharp series of elevator doublets, each held for approximately one second, to vary the normal acceleration by approximately $\pm 1 / 2 \mathrm{G}$ and the AOA by \pm 1 $2^{\circ}$ (Figure 14). The purpose of this maneuver was to provide data to validate the simulation longitudinal response characteristics.

Aileron / Rudder Doublets: The aircraft was initially trimmed for level flight with specific flap and throttle setting to maintain $\mathrm{C}_{\mathrm{T}}$ for a specified airspeed. The pilot input a sharp aileron doublet, paused 1 second, and then input a sharp rudder doublet to vary the lateral acceleration by approximately $\pm 1 / 4 G$ and the sideslip angle by $\pm 5-10^{\circ}$ (Figure 15). The purpose of this maneuver was to provide data to validate the simulation lateral / directional response characteristics.

Acceleration/Deceleration Performance Sweep: The aircraft was initially trimmed at $1.3 \mathrm{~V}_{\mathrm{s}}$ for the specific flap setting. The pilot advanced the throttles to the highest setting to accelerate the airplane to the maximum airspeed at a constant altitude. Once maximum speed was achieved, the pilot reduced throttles to idle to decelerate the airplane while maintaining altitude. During the deceleration, the angle of attack and airplane lift coefficient $\left(C_{L}\right)$ increased until wing stall and $C_{L \text { max }}$ were achieved. Wing stall recovery was initiated and the test point was ended (Figure 22 and Figure 23). The purpose of this maneuver was to determine the aircraft $C_{L}$ curve as a function of angle of attack.

Steady-Heading Sideslip Sweep: The aircraft was initially trimmed for level flight with specific flap and throttle setting to maintain $\mathrm{C}_{\mathrm{T}}$ for a specified airspeed. The pilot gradually input rudder and aileron controls to affect a steady heading sideslip in one direction, and then the other direction. The maximum sideslip angles were limited to $\pm 15^{\circ}$ or the onset of rudder hardover (Figure 16). This purpose of this maneuver was to obtain data for lateral / directional control effectiveness. 
Constant-Airspeed Thrust Transitions: The aircraft was configured with a specific flap for a specified airspeed. The pilot reduced throttles to idle and re-trimmed at the target airspeed. The pilot gradually increased throttle setting up to the maximum continuous power limit while adjusting the pitch attitude to maintain the target airspeed (Figure 17). With flaps deflected and simulated ice on the horizontal tail, the elevator control forces rose quite rapidly during this maneuver ${ }^{6}$. The pilot maintained a running commentary on the perception of control force changes and the longitudinal stability characteristics. In the event of a tail stall, the flying pilot would initiate tail stall recovery techniques by reducing power and pulling the elevator column aft of neutral. The safety pilot was in position to retract flaps, reduce throttles and assist on the yoke if necessary.

Speed Transition: The aircraft was configured with specific flap and throttle setting to maintain $C_{T}$ for specified initial airspeed. The pilot reduced the airspeed by slowly pulling the yoke aft. The throttle position remained fixed. After wing stall speed and angle of attack were established, the nose was lowered for stall recovery. For test points with the flaps deflected, the nose was lowered to reach the maximum speed of $V_{\mathrm{FE}}$ (flap extension speed) or to establish the horizontal tail stall speed limitation (Figure 18). Speed transition test points were conducted as part of the "build up" process in the qualification flights, so the ice configuration tested in Figure 18 is with the horizontal tail and the full-span wing iced, but the vertical tail was clean (ICE01.3).

Throttle-Step Sweep: The aircraft was configured with specific flap and throttle setting to maintain level flight at the specified airspeed. The pilot provided step inputs to the throttles at a magnitude of \pm 5 psi on the torque pressure gauge in a 5-4-3-2-1-1 time sequence (Figure 19). The purpose of this maneuver was to provide data for modeling the thrust effects on pitching moment.

Wind-Up Turns: The aircraft was configured with specific flap and throttle setting to maintain level flight at the specified airspeed. The pilot initiated a bank angle at a roll rate about $2 \mathrm{deg} / \mathrm{s}$ and applied back pressure to gradually increase the G-load while maintaining the specified airspeed (Figure 20). The purpose of this maneuver was to develop stick force per $G$ relationships with and without ice shapes to enable a better stick force model in the flight simulation.

Simulated-Approach / Missed-Approach: This maneuver was flown "head-down" with the flight test engineer acting like a ground control approach (GCA) controller, calling for heading changes of +-10 degrees off a reference heading, and descent rates of 1000, 500, and 0 feet per minute. These simulated course and glide slope corrections were called out in 20 seconds intervals, so the pilot had to make fairly aggressive control and power inputs. At the conclusion of the approach portion of the maneuver, the "controller" commanded a "go-around", and the pilot immediately advanced the throttles to maximum thrust while maintaining the airspeed until a positive rate of climb was established (Figure 21). The purpose of this maneuver was to provide a closed-loop piloting task to gain insight into safe flight characteristics and controllability margins. This maneuver was used in previous flight tests with simulated ice on the horizontal tailplane and provided valuable data into some potential operational issues caused by tailplane icing ${ }^{7}$.

\section{RESULTS AND DISCUSSION}

This entire flight test was conducted in 16 flights (including all qualification flights, a guest pilot flight and a video chase flight) with a total of 29 flight hours of data. From those flights, a total of 575 test maneuvers were performed. Discrete data files for these maneuvers have been extracted from the primary acquisition files and formatted for use with the Bihrle Applied Research's D$\mathrm{Six}^{\circledR}$ simulation software ${ }^{8}$ for validating the simulation models.

A subset of these maneuvers were reviewed and analyzed with a focus on the wing and tail stall characteristics. These results are presented below.

\section{WING \& TAILPLANE STALL CHARACTERISTICS}

In order to be an effective tool to reduce icing accidents, the icing effects flight training device must incorporate the perceivable changes in the iced airplanes performance, stability and control, and handling characteristics. The primary driver of changes in these characteristics is premature flow separation over the wing, and the horizontal and vertical stabilizers. The flow separation causes an increase in drag, a reduced $C_{L \text { max }}$, and a rapid shift in control surface hinge moments. From a flight operations perspective, ice-induced flow separation reduces the flight envelope by increasing wing stall speeds and reducing tail stall speeds. It also increases the pilot work-load during high-precision maneuvers. Since these aspects need to be modeled accurately in the simulation, an emphasis was placed in acquiring and analyzing data during wing and tail stall. The results from these analyses are detailed below.

\section{Acceleration/Deceleration Performance Sweeps:}

This maneuver was used to determine the aircraft $C_{L}$ curve as a function of angle of attack during an idle power condition to minimize thrust effects. The maneuver was performed for each iced configuration for various flap settings. Figure 22 and Figure 23 show the composite results for the "No-Ice", "Horizontal Tail Ice", and the "All Iced" cases for flap settings $0^{\circ}$ and $20^{\circ}$ respectively. The impact of the simulated ice on the lift characteristics is clearly demonstrated.

For $\mathrm{dF}=0^{\circ}$, the difference between the "No-Ice" and the "All Iced" $C_{L \text { max }}$ was about 0.24 , and the change in $\alpha_{\text {stall }}$ 
was about $3^{\circ}$. There was not a measurable difference in these quantities between the baseline and the "Horizontal Tail Ice". This result was expected due to the relatively low total lift contribution from the horizontal tail when $\mathrm{dF}=0^{\circ}$.

For $\mathrm{dF}=20^{\circ}$, the difference between the baseline and the All Iced $C_{L \max }$ was about 0.40 , and the change in $\alpha_{\text {stall }}$ was about $5^{\circ}$. In this flap configuration, there was a measurable difference in $C_{L \text { max }}$ and $\alpha_{\text {stall }}$ between the "No-Ice" and the "Horizontal Tail Ice" cases. The change in $C_{L}$ max was about 0.15 , and the change in $\alpha_{\text {stall }}$ was about $2^{\circ}$. It is likely that this difference was due to the reduced capability of the iced horizontal tail to produce enough down-lift to balance the pitching moment caused by the wing lift. Examination of the tail pressure data during the $C_{L \text { max }}$ portion of these maneuvers indicates a substantially different pressure distribution for similar flight conditions and elevator deflection angles (Figure 24). The pressure distribution with the "Horizontal Tail Ice" indicates a region of flow separation over the upper surface of the tailplane, and an overall reduced tail lift in comparison with the "No-Ice" pressure distribution.

To put these performance values in a context useful for pilot training, Table I below was developed to show the differences in idle-power wing stall speeds for the Twin Otter at a standard weight of $10,000 \mathrm{lbs}$ and sea level conditions.

Table I. Idle-power Wing Stall Speeds* $\mathbf{V}_{\mathbf{s}}$

\begin{tabular}{|l|l|l|l|}
\hline Flap & No ice $\mathbf{V}_{\mathbf{s}}$ & All-Iced $\mathbf{V}_{\mathbf{s}}$ & $\mathbf{1 . 3}^{*} \mathbf{V}_{\mathbf{s}}$ \\
\hline $0^{\circ}$ & 70 kias & 77 kias & 91 kias \\
\hline $20^{\circ}$ & 57 kias & 63 kias & 74 kias \\
\hline
\end{tabular}

* Note: these values listed are for idle-power conditions. For power-on, the values would be lower, but the relative differences would scale accordingly.

Although there was a significant reduction in the $C_{L \text { max }}$ caused by the simulated ice, the typical approach speed of $1.3^{*} V_{s}$ would have been sufficient to keep from stalling the aircraft on approach.

\section{Speed Transition Review:}

As part of the qualification procedure, speed transition test points were conducted during the "build up" process with the simulated ice shapes. Although the purpose of these maneuvers was to establish wing stall and horizontal tail stall speed limitations for safe flight operations, it became apparent in post-flight analysis that these data points were valuable to the research effort. Specifically, these maneuvers provided data of thrust effects on the aircraft's lift coefficient, and on both wing and tail stall.

An example of thrust effects on airplane lift coefficient and $C_{L}$ max are shown in Figure 25. For the flaps extended cases $\left(\mathrm{dF}>15^{\circ}\right)$, there was a significant increase in the lift curve and $C_{L \text { max }}$ due to increased thrust. This increase probably resulted from several contributors: thrust vectoring by the flaps, delayed stall of the inboard wing area, and lift due to the $2.5^{\circ}$ thrust line. This finding is significant for the simulator models since the model development was based on an unpowered wind tunnel model.

The speed transitions also enabled the flight test team to incrementally approach wing and horizontal tail stall. A review of test points for the flaps deflected $20^{\circ}-40^{\circ}$ at specified $\mathrm{C}_{\mathrm{T}}$ produced the data for Table II.

Table II. Speed Envelope for ICE01.3

\begin{tabular}{|c|c|c|c|c|c|c|c|c|c|}
\hline & $\mathbf{C}_{\mathrm{T}}=$ & & & $\mathbf{C}_{\mathrm{T}}=$ & & & $\mathbf{C}_{\mathrm{T}}=$ & & \\
\hline dF & $\begin{array}{l}V_{\text {min }} \\
k t s\end{array}$ & $\begin{array}{l}V_{\text {max }} \\
k t s\end{array}$ & $\begin{array}{l}\Delta \mathrm{V} \\
\mathrm{k} t \mathrm{~s}\end{array}$ & $\begin{array}{l}\mathrm{V}_{\text {min }} \\
k t s\end{array}$ & $\begin{array}{l}\mathbf{V}_{\text {max }} \\
k t s\end{array}$ & $\begin{array}{l}\Delta \mathbf{V} \\
k t s\end{array}$ & $\begin{array}{l}\mathbf{V}_{\text {min }} \\
k t s\end{array}$ & $\begin{array}{l}\mathbf{V}_{\text {max }} \\
k t s\end{array}$ & $\begin{array}{l}\Delta \mathrm{V} \\
\mathrm{kts}\end{array}$ \\
\hline $20^{\circ}$ & 62 & 97 & 35 & 49 & 97 & 48 & 42 & 97 & 55 \\
\hline $25^{\circ}$ & 61 & 85 & 24 & 49 & 85 & 36 & 47 & 85 & 38 \\
\hline $30^{\circ}$ & 60 & 85 & 25 & 51 & 84 & 33 & 48 & 62 & 14 \\
\hline $3^{\circ}$ & 55 & 82 & 27 & 50 & 70 & 20 & 46 & 48 & 2 \\
\hline $40^{\circ}$ & 55 & 73 & 18 & 49 & 52 & 3 & 47 & 50 & 3 \\
\hline
\end{tabular}

In this table, $V_{\text {min }}$ represents the speed at wing stall, and the $V_{\max }$ represents either the flap extension speed $\left(V_{\mathrm{FE}}\right)$, or the speed where the elevator control forces became highly non-linear. During some of these test points, elevator control force reversal was experienced. The point to highlight from this table is the reduced speed range as flap deflection and $\mathrm{C}_{\mathrm{T}}$ were increased. Note that with $\mathrm{dF} \geq 35^{\circ}$ and $\mathrm{C}_{\mathrm{T}}=0.2$, the speed range between wing stall and incipient tail stall was reduced to 2-3 knots. For this reason, no other test maneuvers were conducted with flaps greater than $30^{\circ}$.

\section{Flow Visualization \& Surface Pressure Review:}

Other sources of data to corroborate the wing and tail stall phenomena were the video tapes of the wing and tail tufts, and the pressure belt data. One of the important observations from the wing flow visualization was that the stall started at the trailing edge of the inboard wing, and progressed forward and outward towards the tip (Figure 26). Although the angle of attack where wing stall took place changed with the simulated wing ice, the behavior of the clean wing and iced wing stalls were similar, as described above.

Observations from the tail flow visualization and pressure belt were much different than the wing. Tail flow separation started at the leading edge and progressed aft towards the trailing edge in a full span separation bubble (Figure 27). This tended to be a very dynamic situation on the horizontal tail and was well 
illustrated in the video of the tufts and through the surface pressures. A time series of pressure distributions about the horizontal tail are shown in Figure 28. As the tailplane angle of attack was increased due to an increased airspeed, the suction peak on the lower surface increased with a zone of separation and reattachment aft of the simulated ice shape. The zone of separation increased and decreased chordwise as the tail angle of attack and elevator position changed. Complete flow separation from the tail lower surface is shown in the third distribution in Figure 28 at Time=13:49:13, with some flow reattachment and recovery indicated at Time=13:49:16.

The dynamic nature of the tail flow separation and reattachment also provided a dynamic nature to the elevator control forces. Not only did the separation cause the elevator control forces to vary dynamically, it also caused the control forces to be very non-linear. Since control "feel" is a important parameter for precision maneuvering, and it is highly affected by iceinduced separation, the elevator hinge moment and pilot control forces became key parameters for the simulation models and the flight training device. Therefore, it was important to document the phenomena in order to validate and assess the simulation models and flight training device.

\section{Pilot Assessment:}

Since the Twin Otter wing has no sweep or taper, it generally lends itself to docile and predictable wing stalls with a non-iced wing. The idle-power stalls tended to have a gentle break with no roll tendency in either direction. The effect of thrust and flap deflection altered the stall speeds, but did not have a significant effect on the nature of the non-iced wing stall. Post-stall recovery was accomplished with no secondary stalls or post-stall gyration.

The simulated wing ice shapes caused minor changes in the characteristics of the onset of stall. The buffet speeds and stall speeds increased by 3-8 knots depending on flap configuration. However, the post-stall characteristics were often accompanied by pronounced roll-offs (usually to the left) at the stall break. In addition, secondary stall buffet occasionally occurred during the recovery. Similar stall behavior was experienced in recent flight tests with natural ice accretions. This finding provides confidence that the icing effects due to the simulated ice shapes are representative of the icing effects due to natural icing.

While the Twin Otter has docile wing stall characteristics, it has a known problem with ice contaminated tailplane stall. As discussed above, the simulated ice shape on the tail caused tail stall as the flap deflection and thrust were increased. Associated with the tail stall were highly asymmetric control forces, particularly in the yoke-forward direction. For example, pilots had to overcome nose-down pitching motions by pulling up to $120 \mathrm{lbs}$ during some of the test maneuvers.
Clearly, the tail stall presented difficulty in controlling the airplane. However, controllability was further exacerbated when the issues of tail stall were combined with the wing stall. For example, with flaps deflected to $40^{\circ}$, the speed range between wing stall and the onset of tail stall with high power was only 3 knots. This indicates that a normal wing stall recovery at $\mathrm{dF}=40^{\circ}$ by pushing the yoke forward and increasing thrust could lead to a full tail stall. The controllability was so marginal in this configuration that planned research maneuvers were eliminated from the test matrix.

The Twin Otter flight characteristics offered valuable lessons for icing effects training. Aspects that pilots should experience and be accurately modeled in the simulation are:

- Iced wing and tail stall speeds

- Flap effects and thrust effects

- Non-linear and dynamic control forces

- Control effectiveness

\section{CONCLUSIONS}

The NASA Twin Otter Icing Research Aircraft was successfully used to acquire data to validate simulation models for an icing effects flight training device concept demonstrator. Sixteen flights were conducted to obtain over 500 test points for the simulation model validation effort. This data set is sufficient to fully validate simulation models to be used in an icing effects flight training device.

A subset of this data set was analyzed for this report with an emphasis on wing and tail stall characteristics. Key findings in this analysis were:

- Simulated wing ice shapes significantly reduced the $C_{L \text { max }}$ for all flap settings.

- Increased thrust significantly increased $C_{L}$ and $C_{L \text { max }}$ when flaps were deflected $20^{\circ}$ or more.

- With $\mathrm{dF} \geq 30^{\circ}$, the simulated tail ice caused elevator control force anomalies and tailplane stall depending on thrust setting.

- The wing stall initiated from the trailing edge. The tail stall initiated from the leading edge

- Safe operating margins between wing and tail stall were reduced with simulated ice on the wing and tail as flap deflection and thrust was increased.

- Research pilots observed good similarity in the Twin Otter response characteristics during wing stalls with the simulated ice shape compared to wing stall with natural ice accretions.

- Aspects that need to be in the icing effects flight training device concept demonstrator include iced wing and tail stall speeds, flap and thrust effects, control forces and control effectiveness. 


\section{REFERENCES}

1. Tailplane Icing, NASA Glenn, video tape, 1998. http://icebox.grc.nasa.gov/ext/education/video/video.html

2. Icing for Regional and Corporate Pilots, NASA Glenn, video tape, 1999 http://icebox.grc.nasa.gov/ext/education/video/video.html

3. In-Flight Icing, NASA Glenn, CD-ROM, 2000 http://icebox.grc.nasa.gov/ext/education/cbt/cbt.html

4. Papadakis, M., Gile-Laflin, B., Youssef, G., Ratvasky, T., Aerodynamic Scaling Experiments with Simulated Ice Accretions, AIAA 2001-0833, January 2001

5. Barnhart, B., Dickes, E., Gingras, D., Ratvasky, T., Simulation Model Development for Icing Effects Flight Training, SAE 2002-01-1527, April 2002, NASA TM-2003-212115.

6. Ratvasky, T., Van Zante, J., Sim, A., NASA/FAA Tailplane Icing Program: Flight Test Report, NASA TP-2000-20908, March 2000

7. Ranaudo, R., Ratvasky, T., Van Zante, J., Flying Qualities Evaluation of a Commuter Aircraft With an Ice Contaminated Tailplane, NASA TM-2000210356 SAE 2000-01-1676, September 2000

8. Bihrle Applied Research Inc. http://www.bihrle.com/

\section{CONTACT}

\section{NASA Glenn Research Center}

Thomas P. Ratvasky - Icing Branch

Thomas.P.Ratvasky@grc.nasa.gov

\section{ADDITIONAL SOURCES}

NASA Glenn Technical Report Server: http://gltrs.grc.nasa.gov/GLTRS/

\section{DEFINITIONS, ACRONYMS, ABBREVIATIONS}

$\begin{array}{ll}\text { AvSP } & \text { Aviation Safety Program } \\ \mathrm{AOA} & \text { Angle of Attack (deg) } \\ \mathrm{Az} & \text { Vertical Acceleration (ft/s2) } \\ \mathrm{C}_{\mathrm{T}} & \text { Propeller Thrust Coefficient } \\ \mathrm{C}_{\mathrm{T} L} & \text { Left Propeller Thrust Coefficient } \\ \mathrm{C}_{\mathrm{T} R} & \text { Right Propeller Thrust Coefficient } \\ \mathrm{C}_{\mathrm{L}} & \text { Lift Coefficient } \\ \mathrm{C}_{\mathrm{L}} \text { a/c } & \text { Aircraft Lift Coefficient } \\ \mathrm{C}_{\mathrm{m}} & \text { Pitching Moment Coefficient } \\ \mathrm{dF} & \text { Flap Deflection Angle (deg) } \\ \text { delA } & \text { Aileron Deflection Angle (deg) } \\ \text { delE } & \text { Elevator Deflection Angle (deg) } \\ \text { deIR } & \text { Rudder Deflection Angle (deg) }\end{array}$

GCA Ground Control Approach

p Roll Rate (deg/s)

q Pitch Rate (deg/s)

$r \quad$ Yaw Rate (deg/s)

SWAP System Wide Accident Prevention Project

Thtl L Left Throttle Position (\%)

Thtl R Right Throttle Position (\%)

VIAS Velocity Indicated airspeed

$V_{s} \quad$ Stall Speed

$V_{\text {yse }} \quad$ Single-Engine Climb Speed

$V_{\text {mca }} \quad$ Minimum Control Airspeed

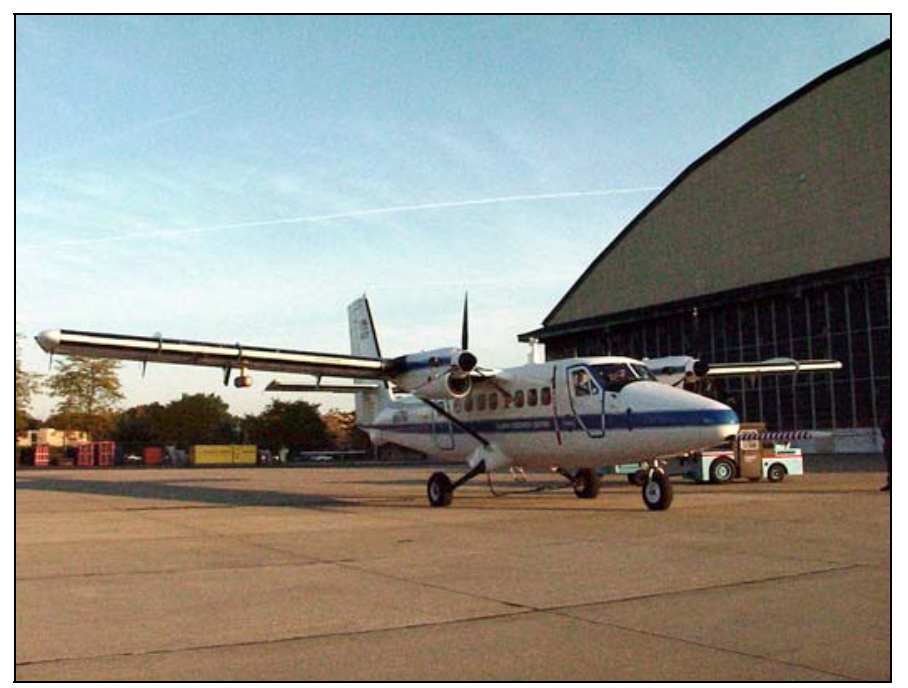

Figure 1. NASA Twin Otter Icing Research Aircraft

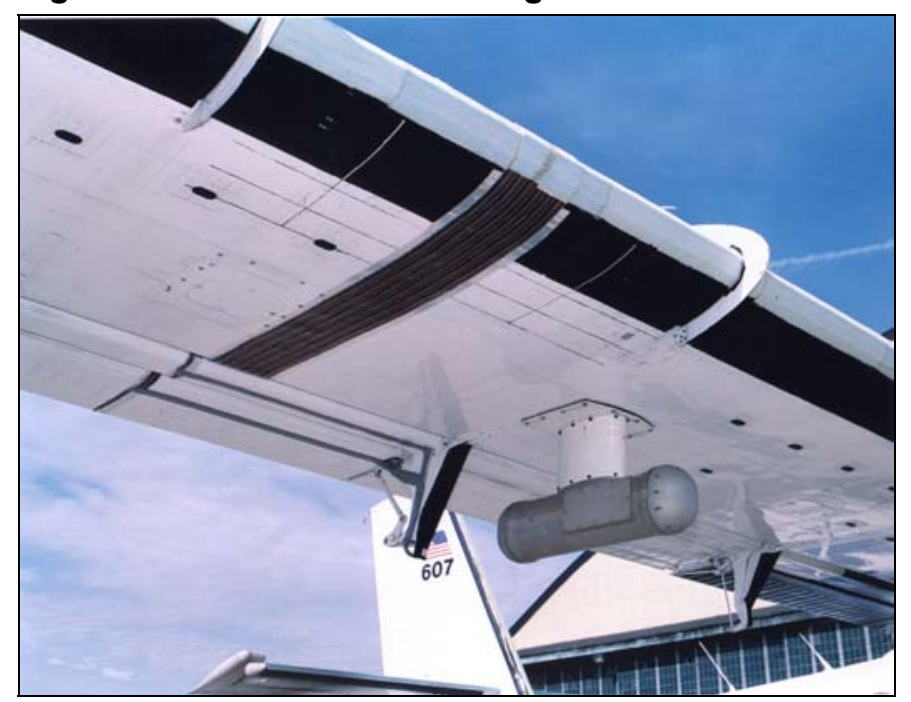

Figure 2. Wing Pressure Belt \& Pod 


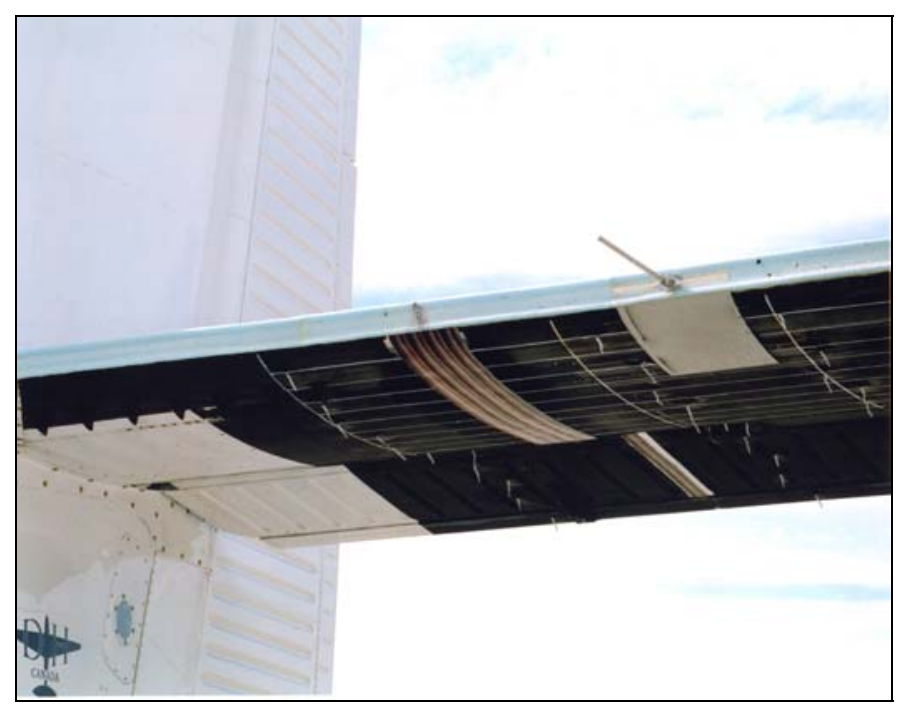

Figure 3. Tail Pressure Belt \& Flow Probe

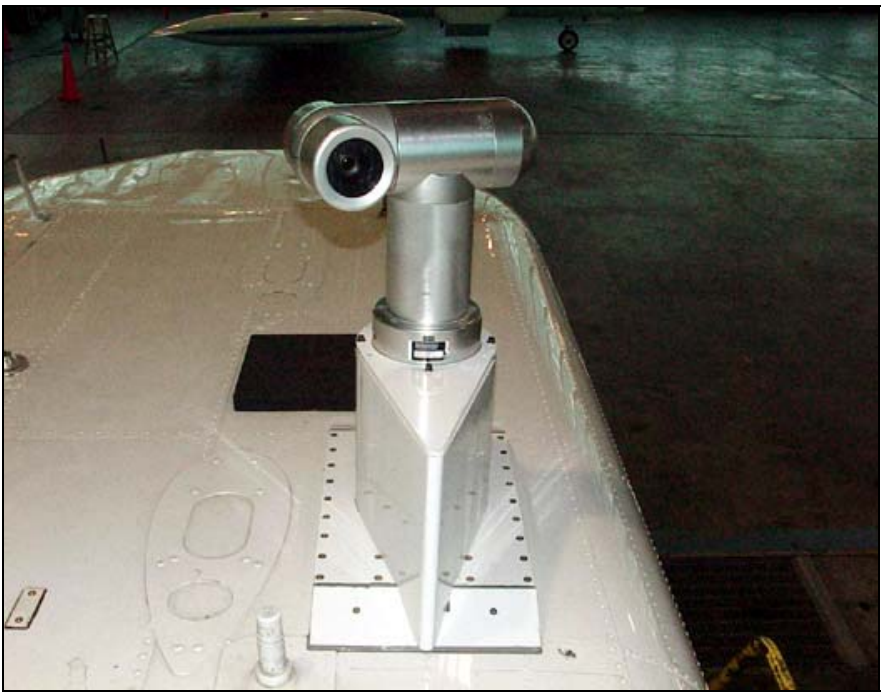

Figure 4. Overhead Video Camera

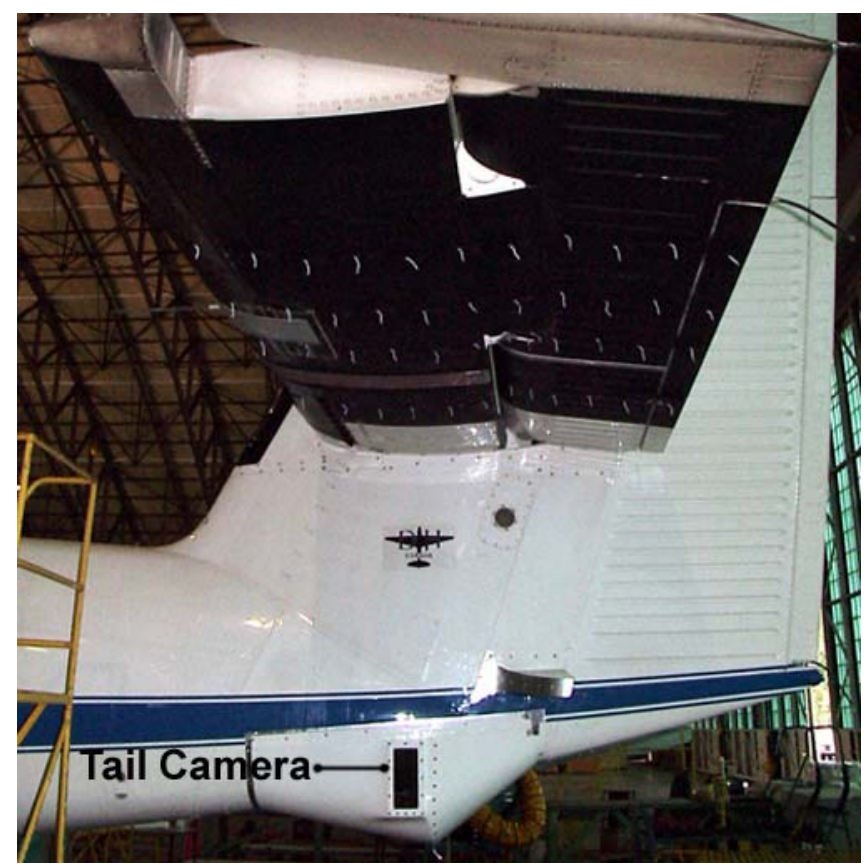

Figure 5. Tail Video Camera

NASA/TM-2003-212114

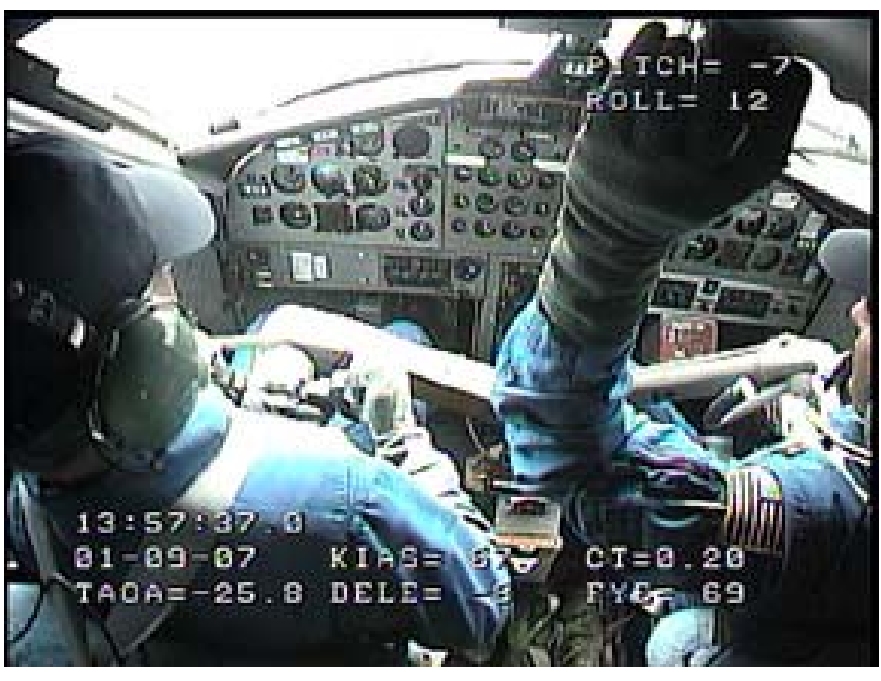

Figure 6. Flight Deck During Wing Stall

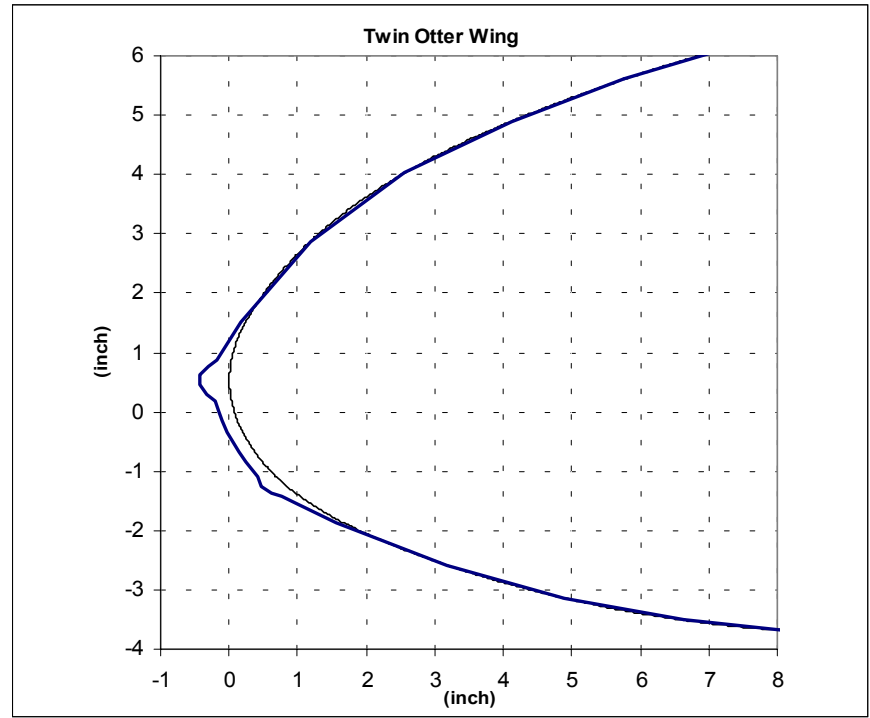

Figure 7. Simulated Wing Ice Profile

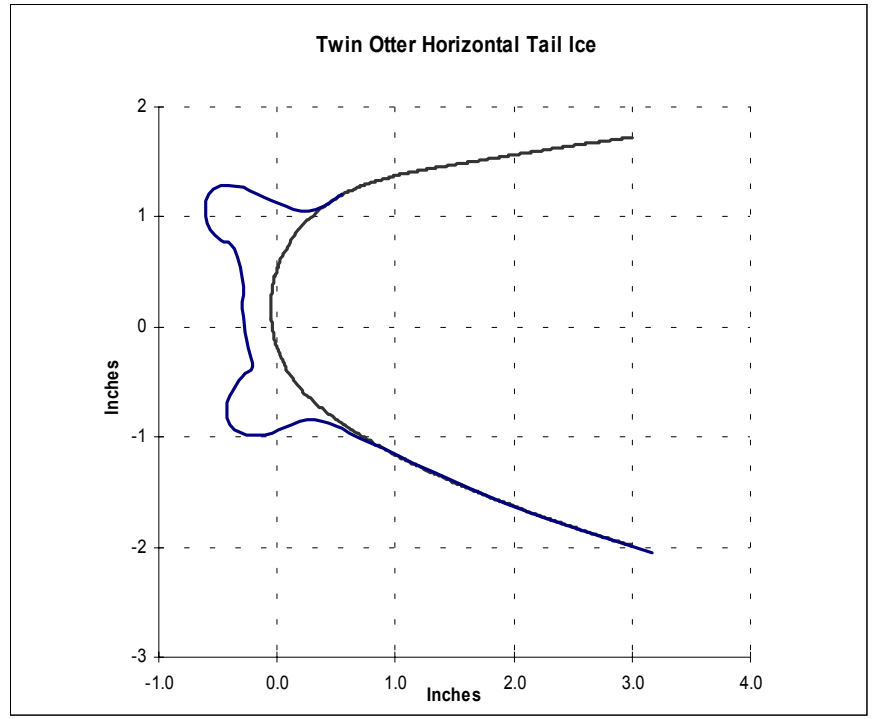

Figure 8. Simulated Horizontal Tail Ice Profile 


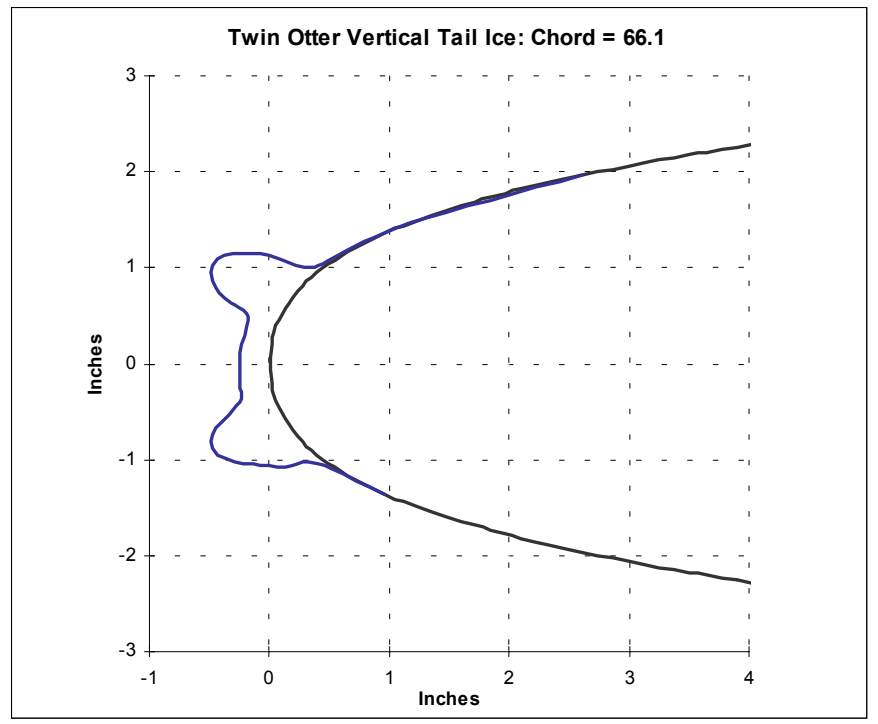

Figure 9. Simulated Vertical Tail Tip Ice Profile

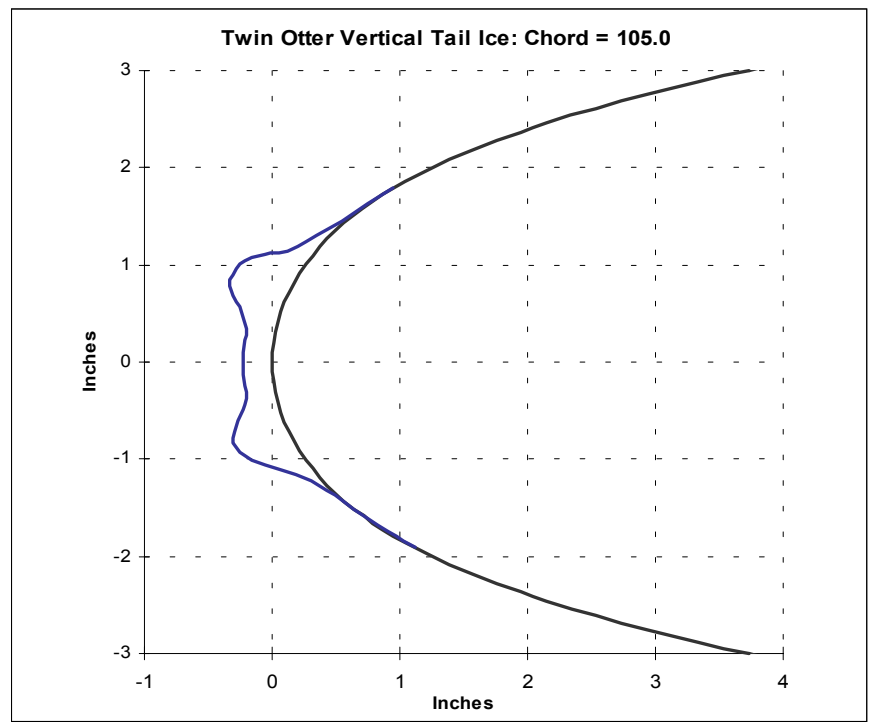

Figure 10. Simulated Vertical Tail Root Ice Profile

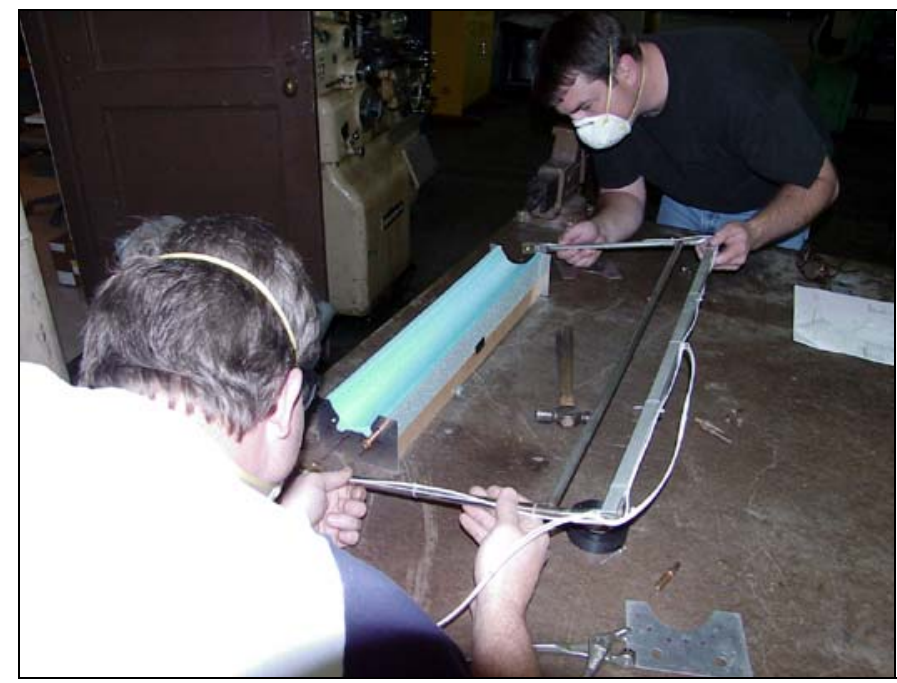

Figure 11. Simulated Tail Ice Fabrication

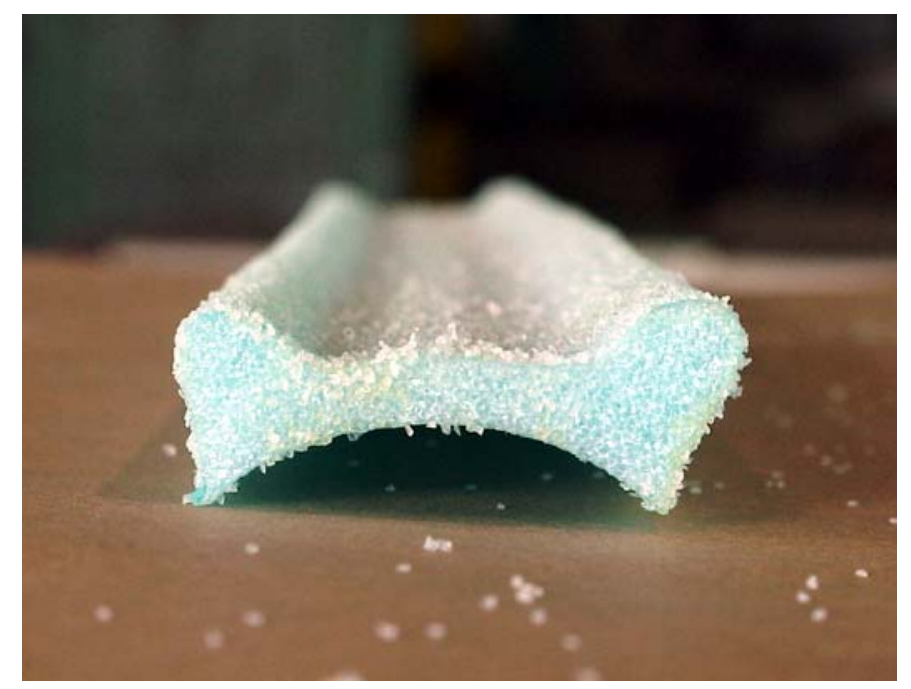

Figure 12. Simulated Tail Ice With Grit Roughness

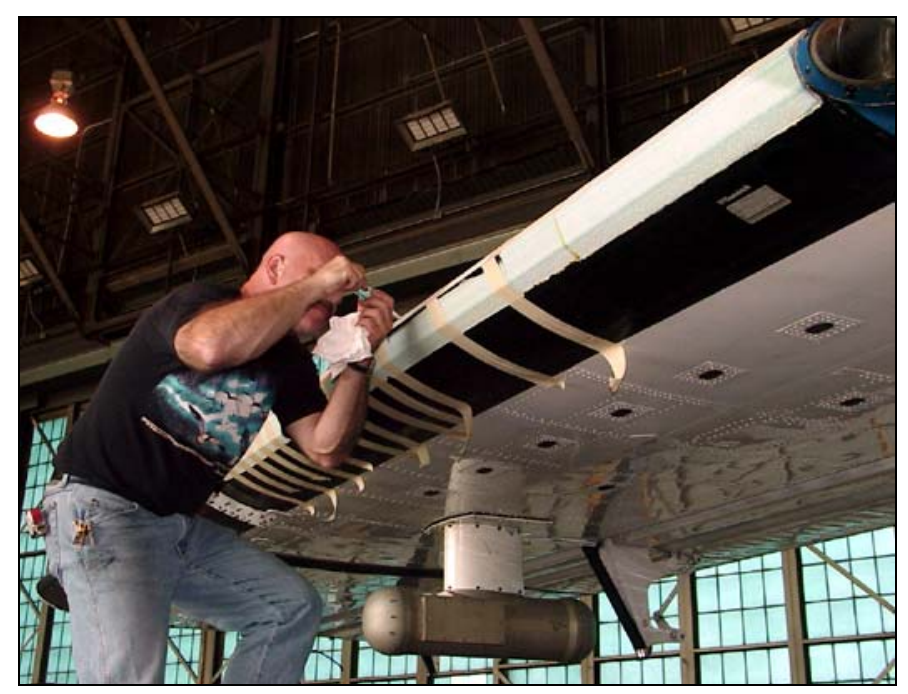

Figure 13. Simulated Ice Installation 


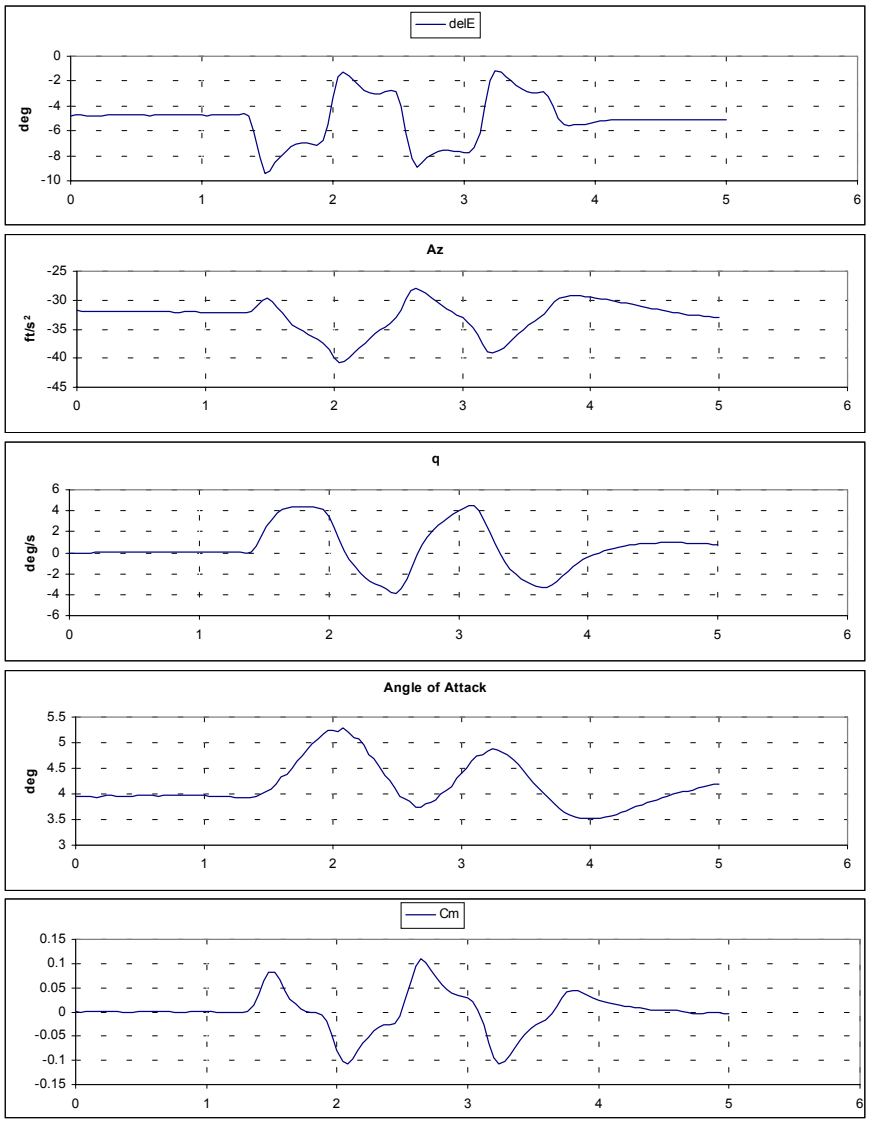

Figure 14. Elevator Doublet, ICE02, $d F=0, C_{T}=0.14$

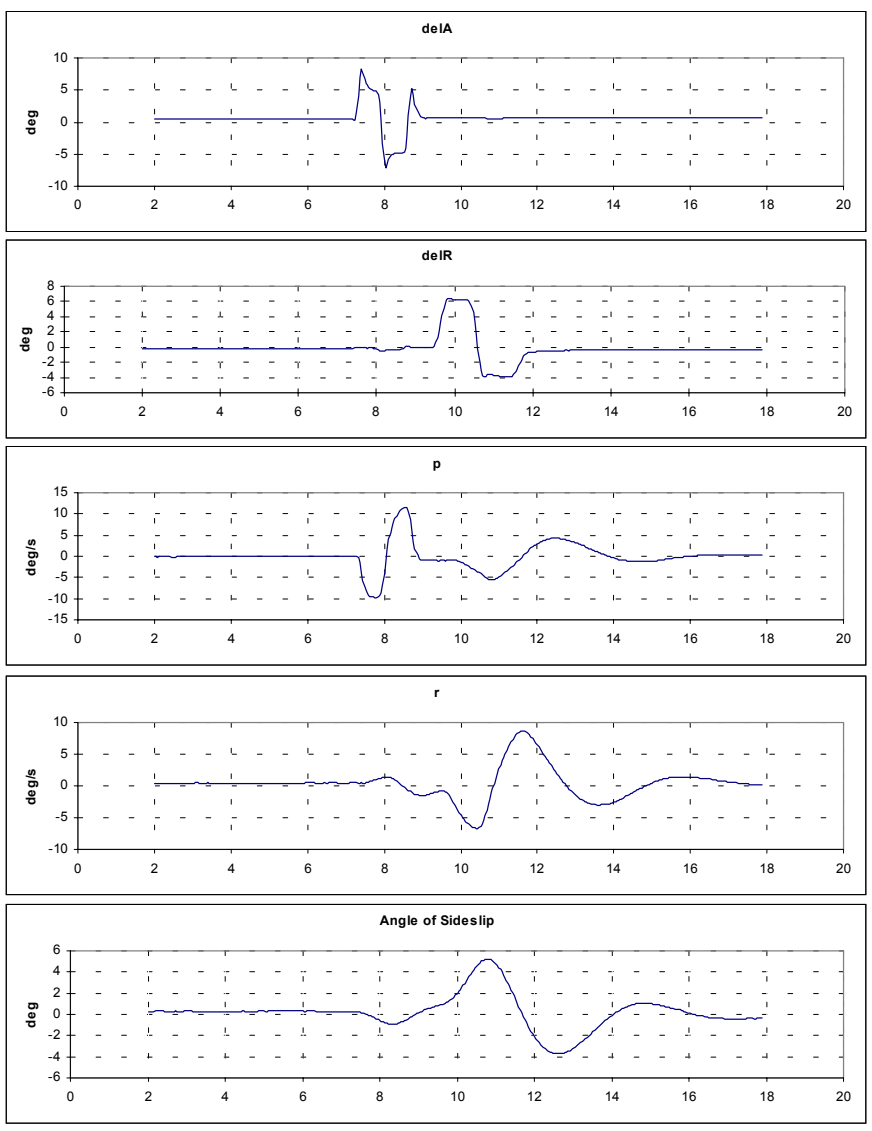

Figure 15. Aileron/Rud Doublet, ICE02, $d F=0, C_{T}=0.14$ NASA/TM-2003-212114
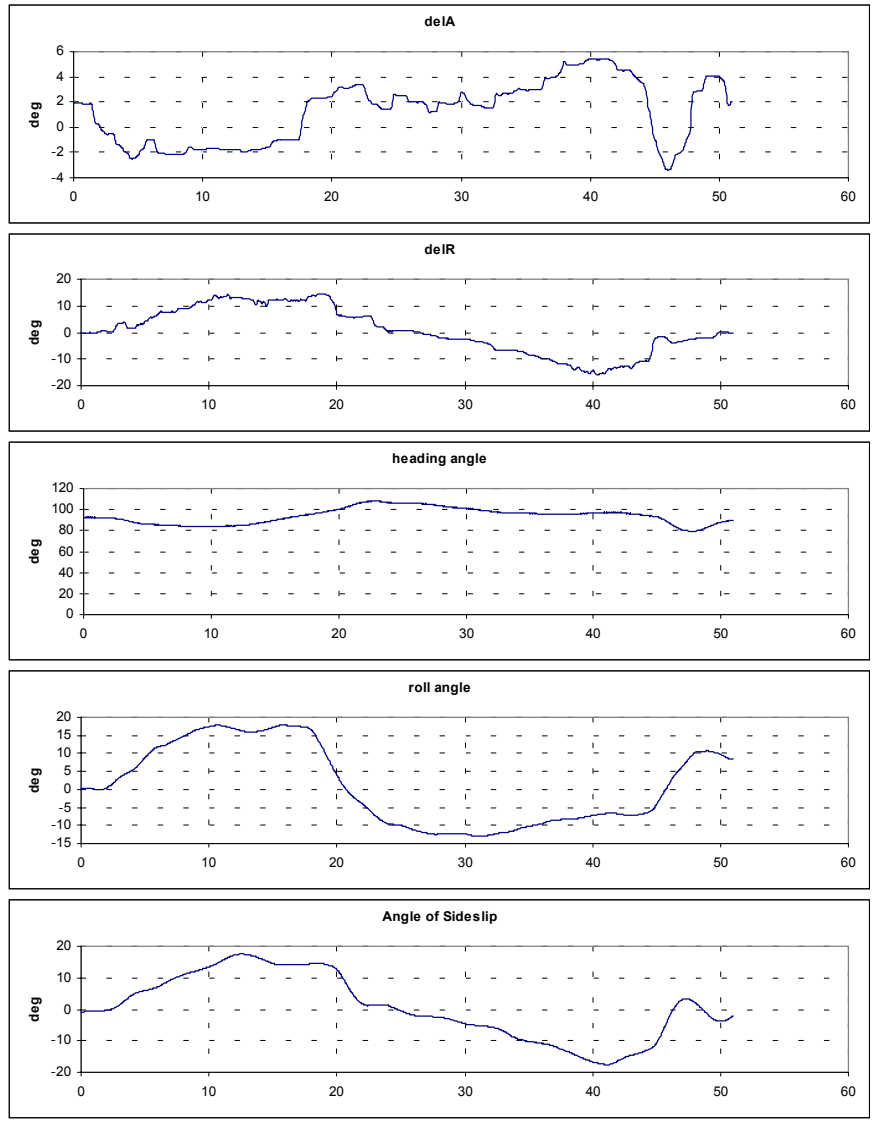

Figure 16. Sideslip Sweep, ICE02, dF=20, $C_{T}=0.20$
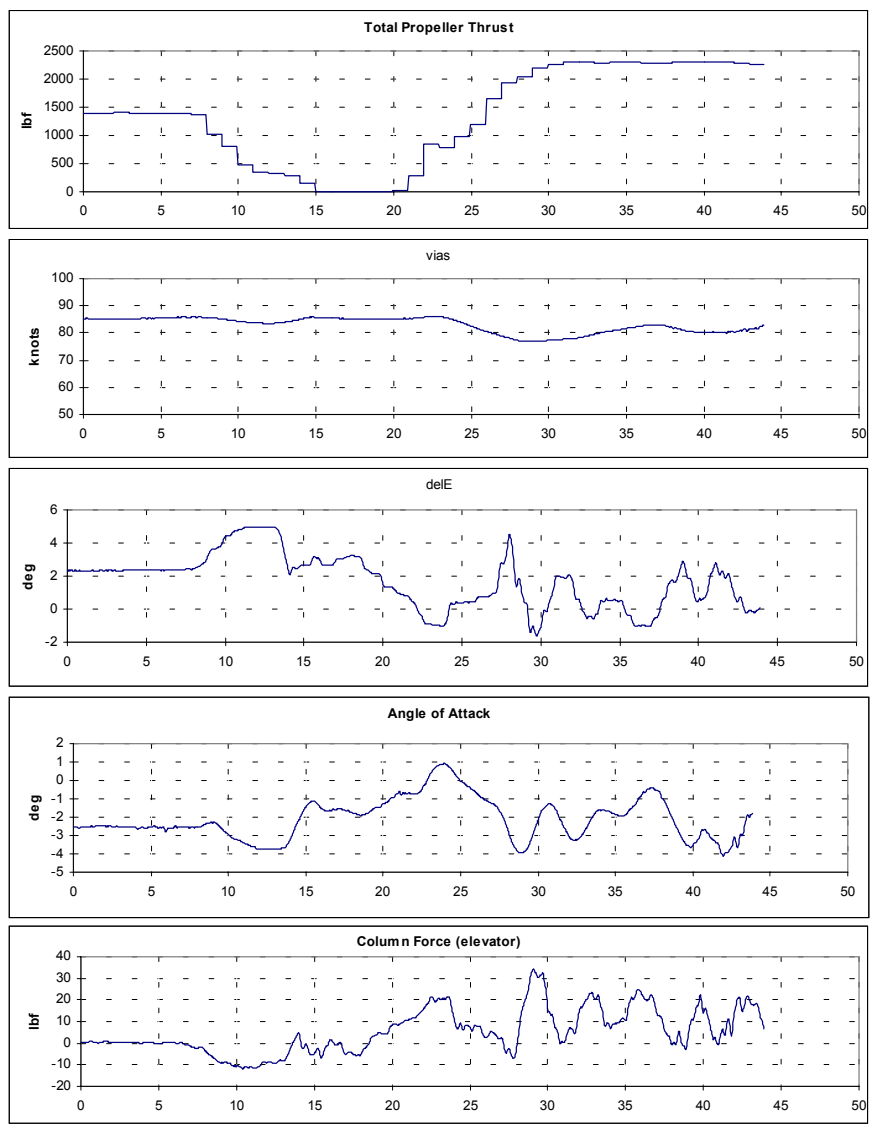

Figure 17. Thrust Transition, ICE02, dF=20 

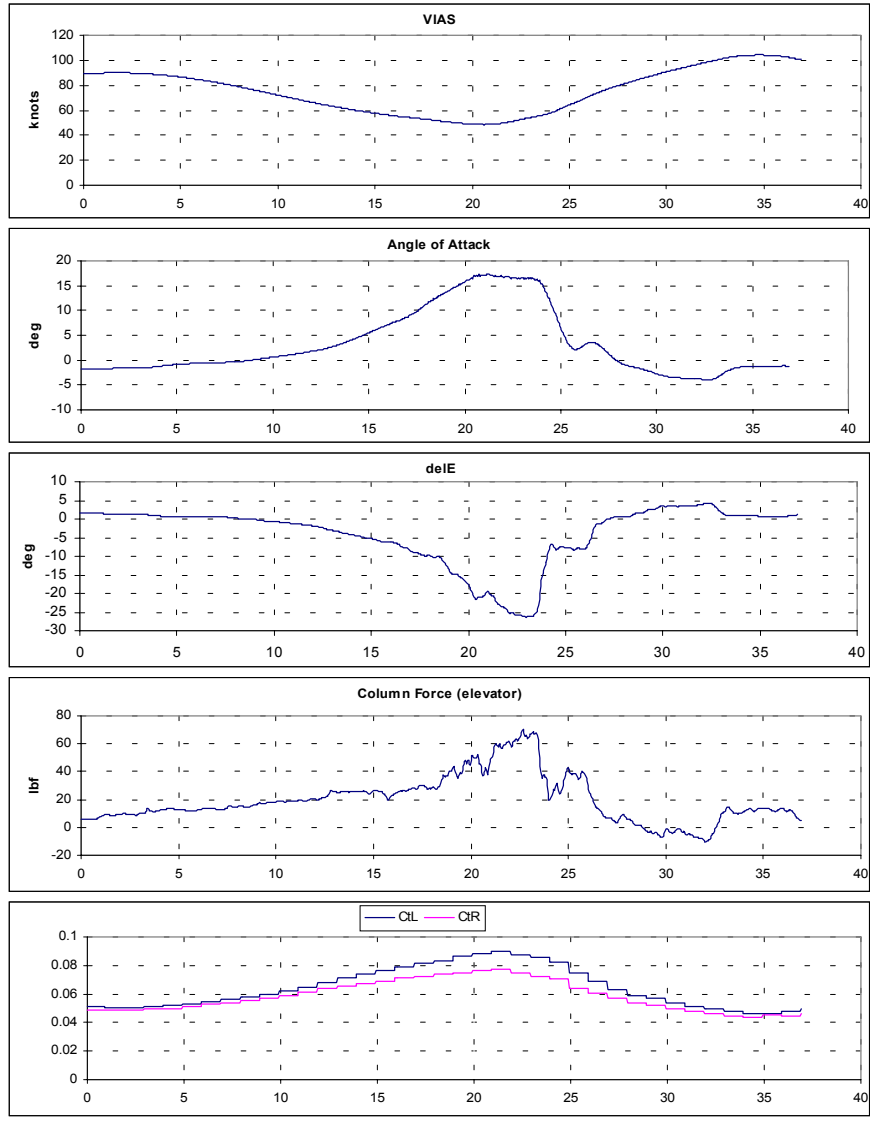

Figure 18. Speed Transition, ICE01.3, dF=20
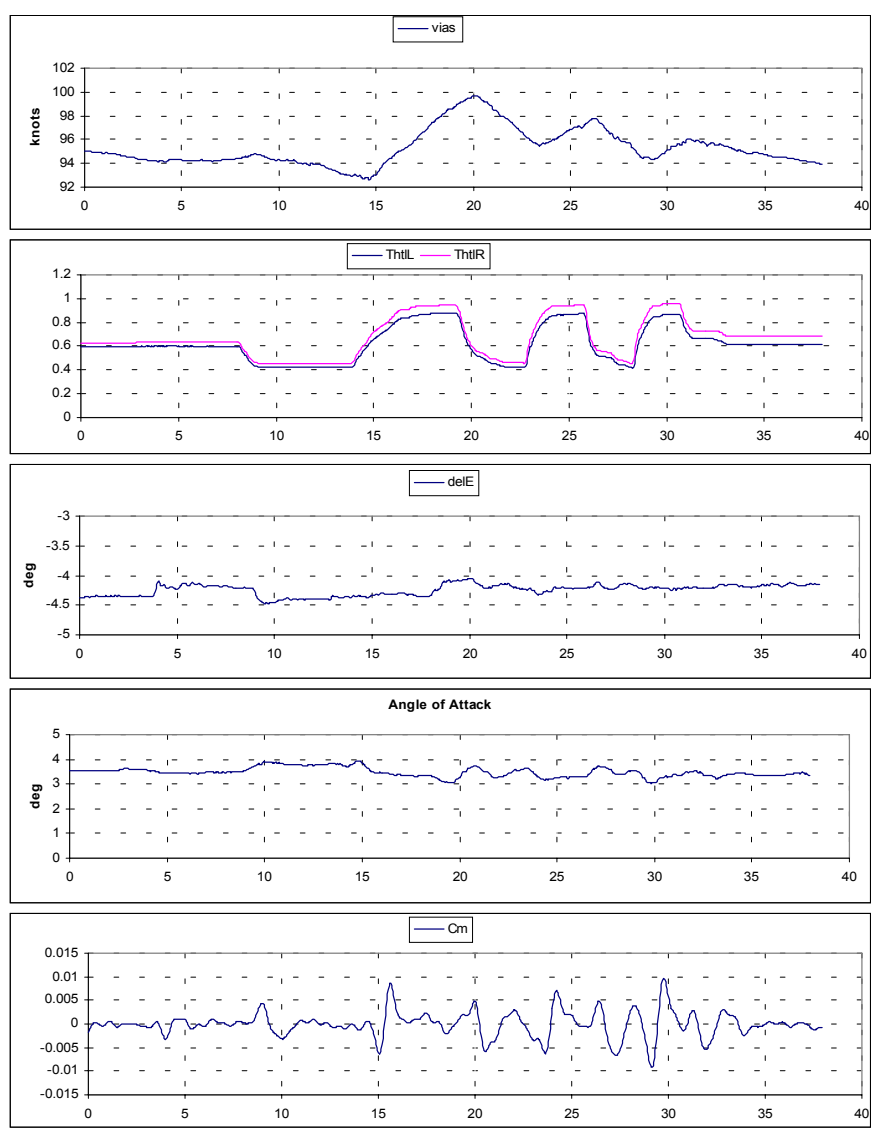

Figure 19. Throttle Step Sweep, ICE02, dF=0

NASA/TM-2003-212114
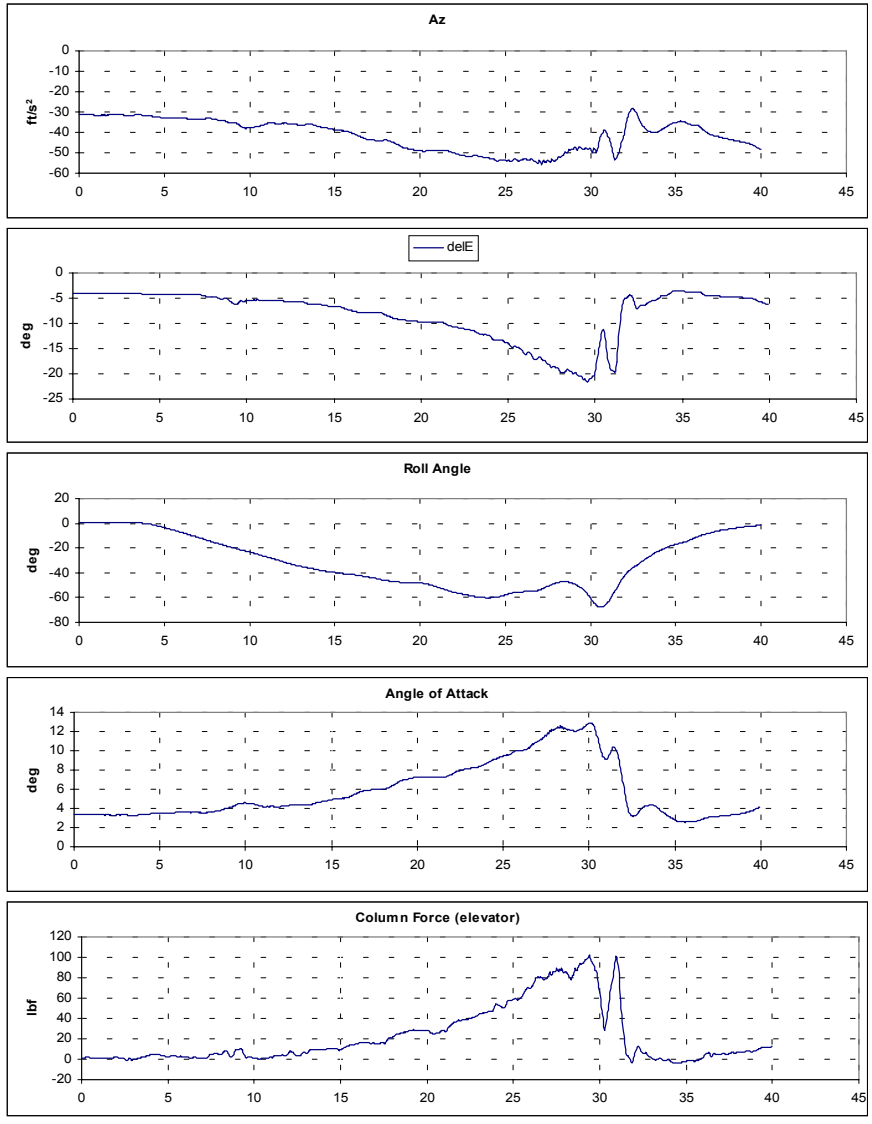

Figure 20. Wind-up Turn, ICE02, dF=0, V=95
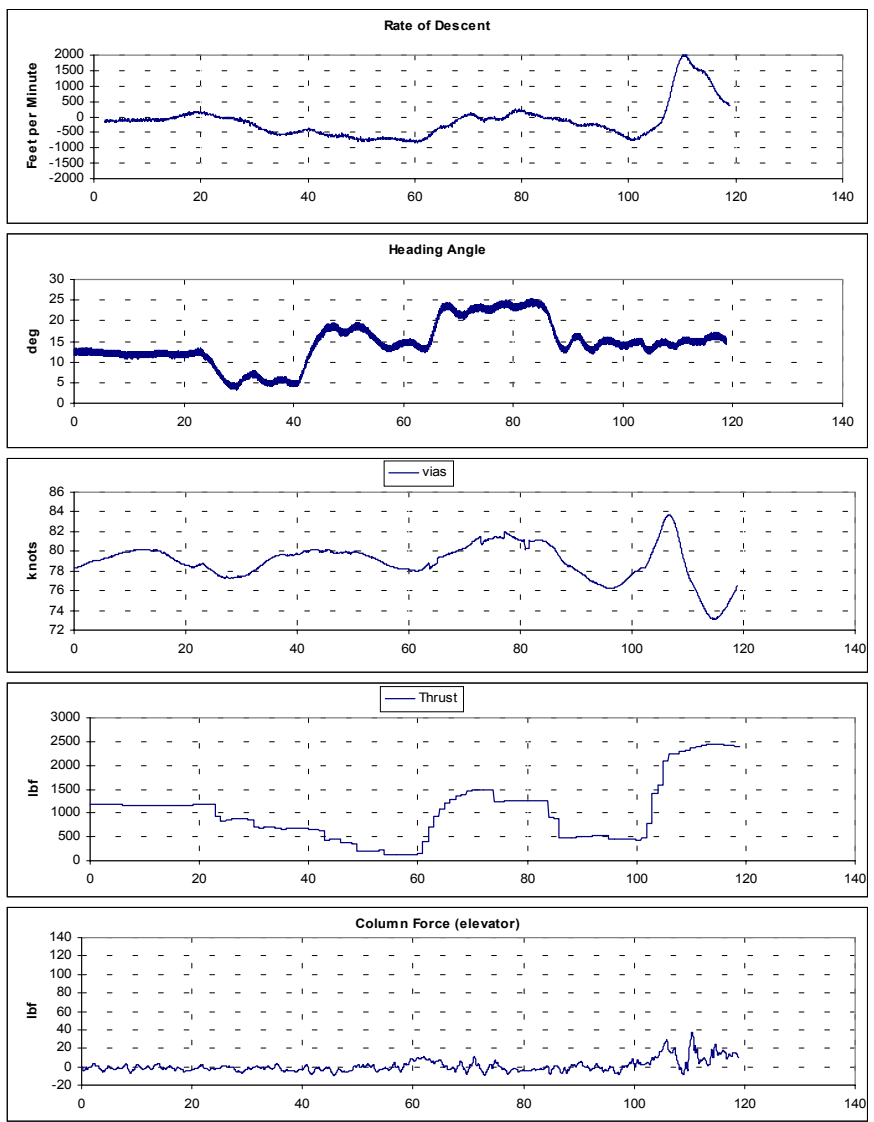

Figure 21. Simulated/Missed Approach, ICE02, $\mathrm{dF}=\mathbf{2 0}$ 


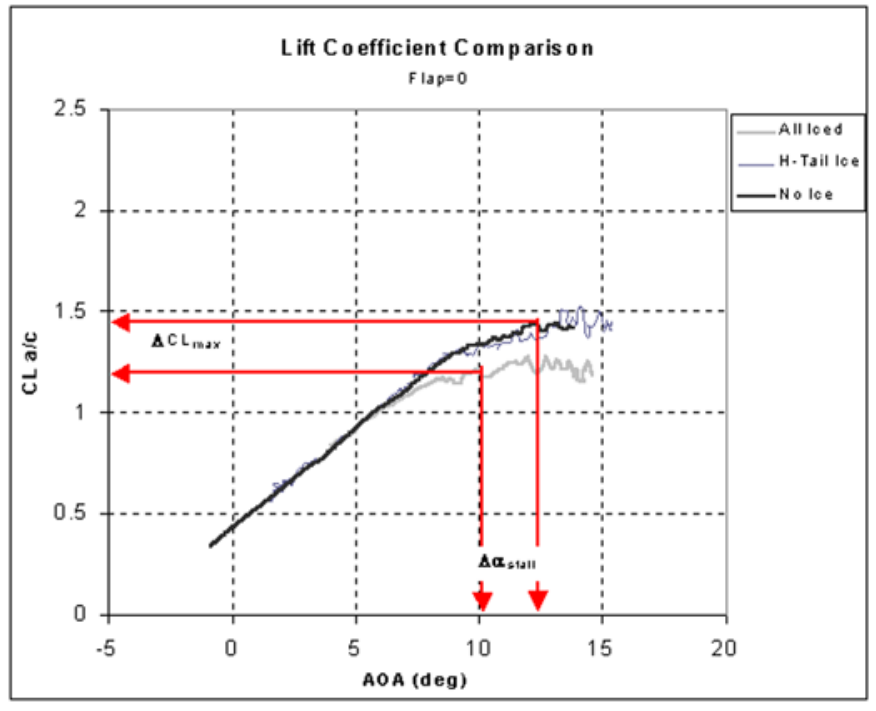

Figure 22. Idle-Power Decel Lift Curve, $d F=0$

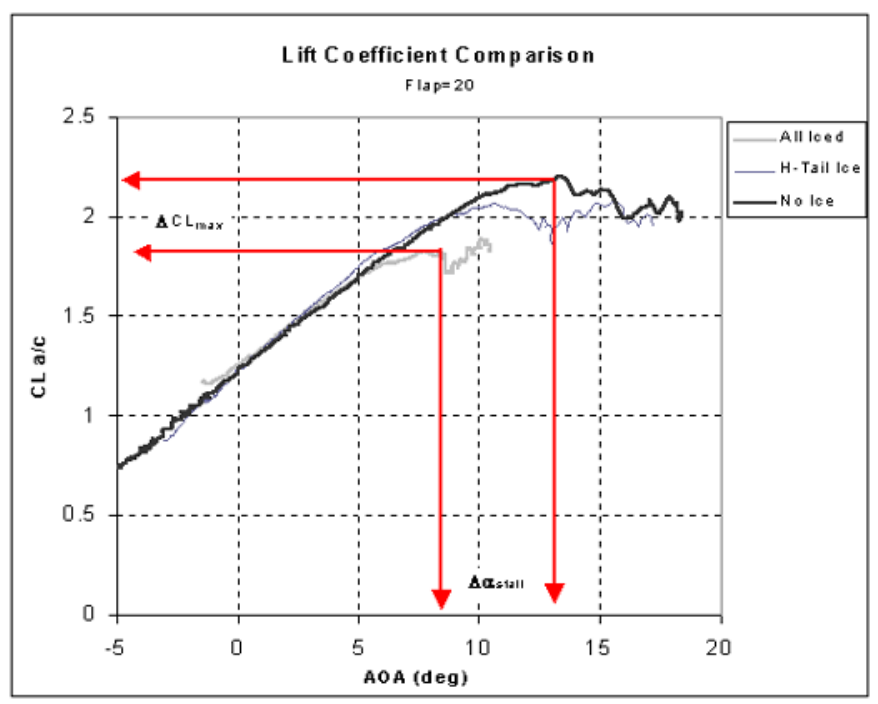

Figure 23. Idle-Power Decel Lift Curve, $\mathrm{dF}=\mathbf{2 0}$
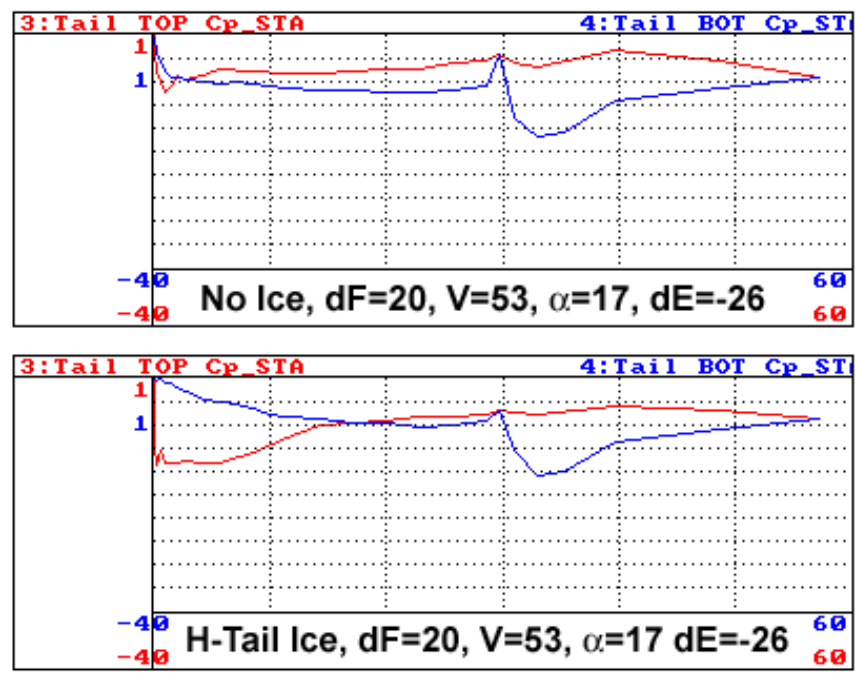

Figure 24. Tail Pressure Profile Comparison at $C_{L \text { max }}$

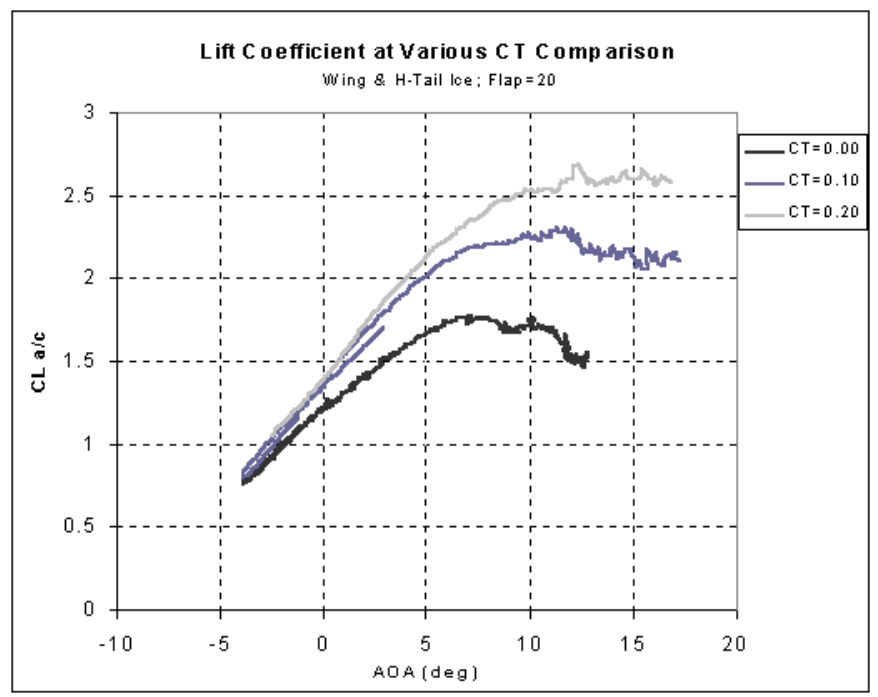

Figure 25. Lift Curves For Various $\mathrm{C}_{\mathrm{T}}, \mathrm{ICE1.3,} \mathrm{dF}=20$

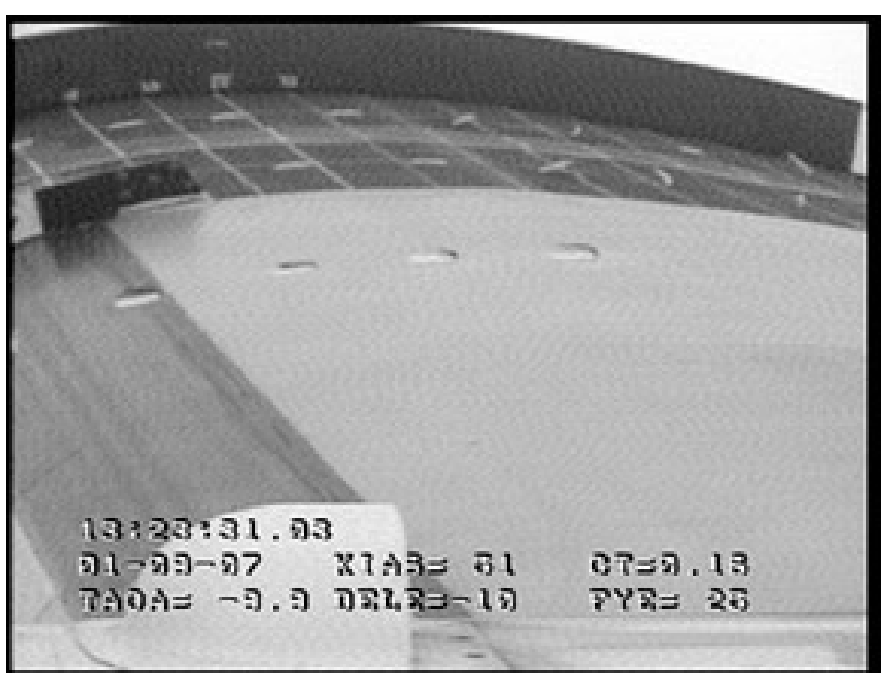

Figure 26. Outboard Right Wing Upper Surface With Tufts During Wing Stall

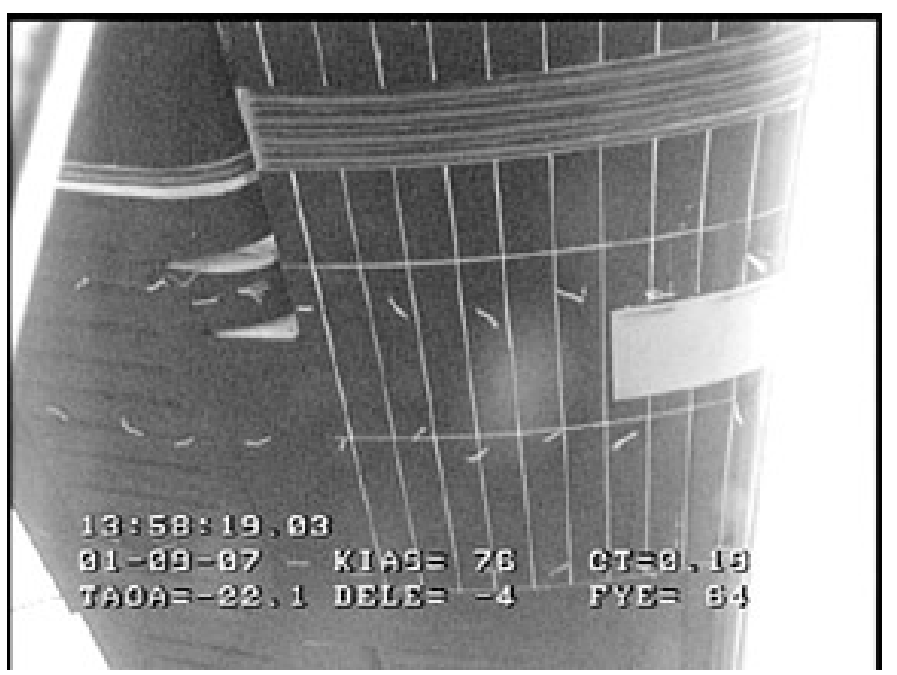

Figure 27. Left Horizontal Tail Lower Surface With Tufts During Tail Stall 


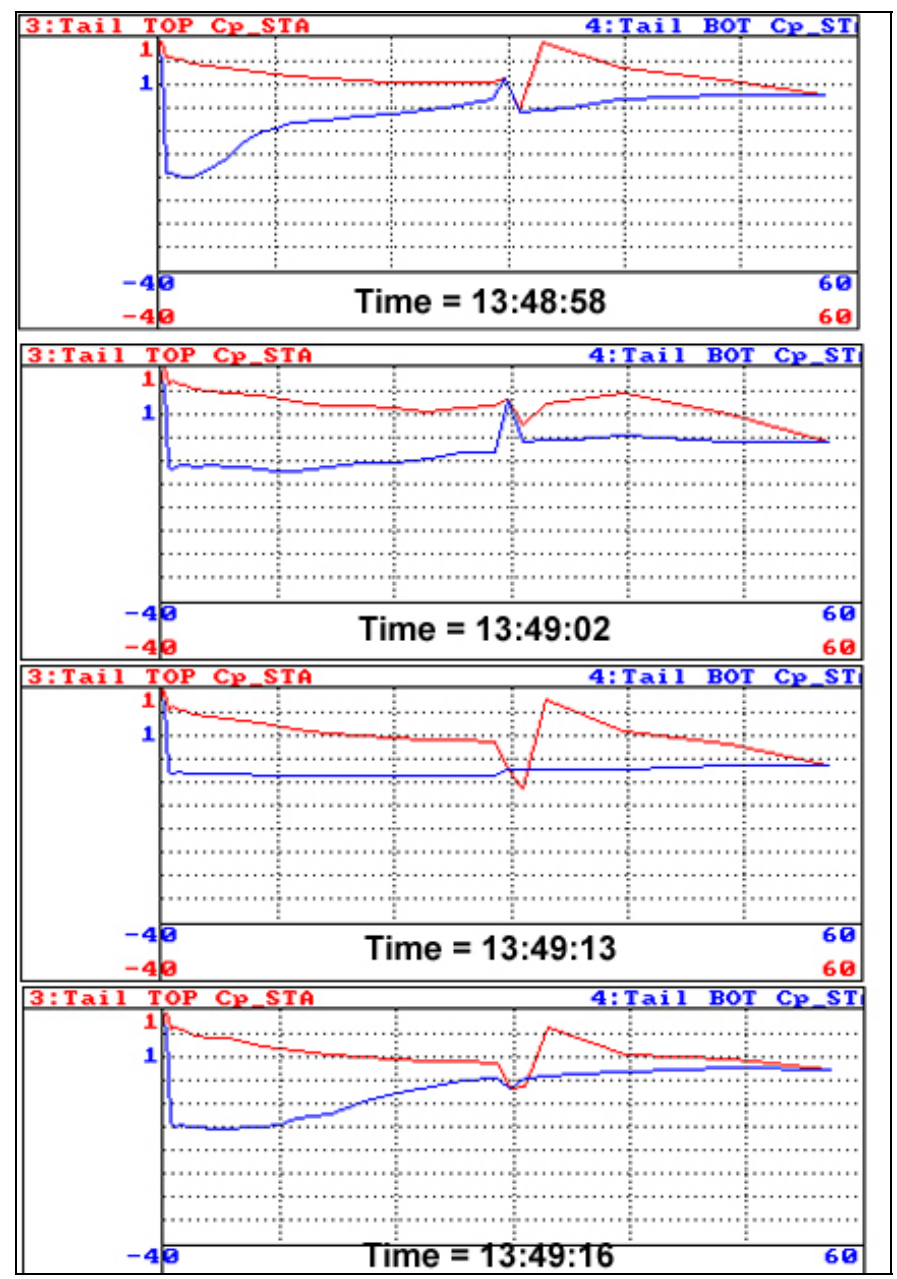

Figure 28. Tail Stall Pressure Profile Sequence 
Public reporting burden for this collection of information is estimated to average 1 hour per response, including the time for reviewing instructions, searching existing data sources, gathering and maintaining the data needed, and completing and reviewing the collection of information. Send comments regarding this burden estimate or any other aspect of this collection of information, including suggestions for reducing this burden, to Washington Headquarters Services, Directorate for Information Operations and Reports, 1215 Jefferson Davis Highway, Suite 1204, Arlington, VA 22202-4302, and to the Office of Management and Budget, Paperwork Reduction Project (0704-0188), Washington, DC 20503.

\begin{tabular}{|l|l|l|}
\hline 1. AGENCY USE ONLY (Leave blank) & $\begin{array}{c}\text { 2. REPORT DATE } \\
\text { April } 2003\end{array}$ & $\begin{array}{r}\text { 3. REPORT TYPE AND DATES COVERED } \\
\text { Technical Memorandum }\end{array}$ \\
\hline
\end{tabular}

4. TITLE AND SUBTITLE 5. FUNDING NUMBERS

Iced Aircraft Flight Data for Flight Simulator Validation

6. AUTHOR(S)

WBS-22-728-20-01

Thomas P. Ratvasky, Kurt Blankenship, William Rieke, and David J. Brinker

7. PERFORMING ORGANIZATION NAME(S) AND ADDRESS(ES)

8. PERFORMING ORGANIZATION

National Aeronautics and Space Administration

John H. Glenn Research Center at Lewis Field

Cleveland, Ohio 44135-3191 REPORT NUMBER

E-13766

9. SPONSORING/MONITORING AGENCY NAME(S) AND ADDRESS(ES)

10. SPONSORING/MONITORING

National Aeronautics and Space Administration

Washington, DC 20546-0001

AGENCY REPORT NUMBER

NASA TM-2003-212114

SAE-2002-01-1528

\section{SUPPLEMENTARY NOTES}

Prepared for the General Aviation Technology Conference and Exhibition 2002 sponsored by the Society of Automotive Engineers, Wichita, Kansas, April 16-18, 2002. Responsible person, Thomas P. Ratvasky, organization code 5840, 216-433-3905.

12a. DISTRIBUTION/AVAILABILITY STATEMENT

12b. DISTRIBUTION CODE

Unclassified - Unlimited

Subject Category: 05

Distribution: Nonstandard

Available electronically at http://gltrs.grc.nasa.gov

This publication is available from the NASA Center for AeroSpace Information, 301-621-0390.

13. ABSTRACT (Maximum 200 words)

NASA is developing and validating technology to incorporate aircraft icing effects into a flight training device concept demonstrator. Flight simulation models of a DHC-6 Twin Otter were developed from wind tunnel data using a subscale, complete aircraft model with and without simulated ice, and from previously acquired flight data. The validation of the simulation models required additional aircraft response time histories of the airplane configured with simulated ice similar to the subscale model testing. Therefore, a flight test was conducted using the NASA Twin Otter Icing Research Aircraft. Over 500 maneuvers of various types were conducted in this flight test. The validation data consisted of aircraft state parameters, pilot inputs, propulsion, weight, center of gravity, and moments of inertia with the airplane configured with different amounts of simulated ice. Emphasis was made to acquire data at wing stall and tailplane stall since these events are of primary interest to model accurately in the flight training device. Analyses of several datasets are described regarding wing and tailplane stall. Key findings from these analyses are that the simulated wing ice shapes significantly reduced the $\mathrm{C}_{\mathrm{L} \text { max }}$, while the simulated tail ice caused elevator control force anomalies and tailplane stall when flaps were deflected $30^{\circ}$ or greater. This effectively reduced the safe operating margins between iced wing and iced tail stall as flap deflection and thrust were increased. This flight test demonstrated that the critical aspects to be modeled in the icing effects flight training device include: iced wing and tail stall speeds, flap and thrust effects, control forces, and control effectiveness.

14. SUBJECT TERMS

15. NUMBER OF PAGES

Aircraft icing; Flight simulation; Flight simulators; Flight safety

19

\begin{tabular}{|c|c|c|}
\hline $\begin{array}{c}\text { 17. SECURITY CLASSIFICATION } \\
\text { OF REPORT }\end{array}$ & $\begin{array}{c}\text { 18. SECURITY CLASSIFICATION } \\
\text { OF THIS PAGE }\end{array}$ & $\begin{array}{c}\text { 19. SECURITY CLASSIFICATION } \\
\text { OF ABSTRACT } \\
\text { Unclassified }\end{array}$ \\
Unclassified & Unclassified
\end{tabular}

NSN 7540-01-280-5500

Standard Form 298 (Rev. 2-89)

Prescribed by ANSI Std. Z39-18 298-102 

